"This accepted author manuscript is copyrighted and published by Elsevier. It is posted here by agreement between Elsevier and MTA. The definitive version of the text was subsequently published in [JOURNAL OF ORGANOMETALLIC CHEMISTRY 797: 140-152 (2015)

doi:10.1016/j.jorganchem.2015.08.013]. Available under license CC-BY-NC-ND."

\title{
A study on the optical resolution of 1-isopropyl-3-methyl-3-phospholene 1- oxide and its use in the synthesis of borane and platinum complexes
}

Péter Bagi, ${ }^{1}$ Kinga Juhász, ${ }^{1}$ István Timári, ${ }^{2}$ Katalin E. Kövér, ${ }^{2}$ Dávid Mester, ${ }^{3,4}$ Mihály Kállay, ${ }^{3,4}$ Miklós Kubinyi, ${ }^{4,5}$ Tibor Szilvási, ${ }^{6}$ Péter Pongrácz, ${ }^{7}$ László Kollár, ${ }^{7}$ Konstantin Karaghiosoff, ${ }^{8}$ Mátyás Czugler, ${ }^{1}$ László Drahos, ${ }^{5}$ Elemér Fogassy ${ }^{1}$ and György Keglevich $^{1, *}$

${ }^{1}$ Department of Organic Chemistry and Technology, Budapest University of Technology and Economics, 1521 Budapest, Hungary

${ }^{2}$ Department of Inorganic and Analytical Chemistry, University of Debrecen, 4032 Debrecen, Hungary

${ }^{3}$ MTA-BME Lendület Quantum Chemistry Research Group at the

${ }^{4}$ Department of Physical Chemistry and Material Science, Budapest University of Technology and Economics, 1521 Budapest, Hungary

${ }^{5}$ Research Centre for Natural Sciences, Hungarian Academy of Sciences, 1525 Budapest,

Hungary

${ }^{6}$ Department of Inorganic and Analytical Chemistry, Budapest University of Technology and Economics, 1521 Budapest, Hungary

${ }^{7}$ Department of Inorganic Chemistry, University of Pécs and Szentágothai Research Center, 7624 Pécs, Hungary

${ }^{8}$ Department Chemie und Biochemie, Ludwig-Maximilians-Universität München, 81377

München, Germany

\section{ABSTRACT}

A 1-isopropyl-3-phospholene 1-oxide was prepared and the two enantiomers were isolated from the racemate by resolution using optically active TADDOL derivatives or the acidic $\mathrm{Ca}^{2+}$ salts of (-)-O,O-diaroyl-(2R,3R)-tartaric acids. The single crystal X-ray structure of the 
1-isopropyl-3-phospholene oxide - spiro-TADDOL 1:2 associate revealed the mode of binding between the host and guest molecules. The role of the interactions between the three molecules was supported not only by the contact data, but also force field and semiempirical calculations. Beside X-ray analysis, the absolute configuration of the P-stereogenic center was also determined on the basis of $\mathrm{CD}$ spectroscopy and high level quantum chemical calculations. The racemic and optically active 1-isopropyl-3-phospholenes obtained after deoxygenation were converted to the corresponding borane complexes and $\mathrm{Pt}(\mathrm{II})$ complexes. Stereostructure of the latter species was evaluated by high level quantum chemical calculations and the Pt complexes were tested as catalysts in the hydroformylation of styrene.

\section{Keywords:}

3-Phospholene oxide, Optical resolution, X-ray structure, Theoretical calculations, Ptcomplexes, Hydroformylation

\section{Introduction}

The transition metal phosphine complexes are widely used catalysts in homogenous catalytic reactions, such as hydrogenation and hydroformylation that underlines the importance of phosphines among organophosphorus compounds [1,2]. Among the phosphine ligands, the P-stereogenic $\mathrm{P}(\mathrm{III})$-compounds are of great importance. The P-heterocyclic derivatives form a special group [3]. However, there are only a few examples in the literature for P-heterocyclic phosphines bearing an asymmetric phosphorus atom [4-6].

Although an increasing number of examples can be found in the literature for the asymmetric syntheses of P-stereogenic compounds [7-9], in most cases the resolution of the corresponding racemic compounds is the method of choice for the preparation of optically active organophosphorus compounds including P-heterocyclic derivatives with a Pstereogenic center $[6,10]$. Many examples can be found in the literature for the resolution of 
cyclic P-chiral phosphines, phosphine oxides and phosphonium salts via the formation of covalent diasteromers [11-13], diastereomeric coordination [14-19], molecular complexes $[10,20,21]$ or diastereomeric salts [22-27].

In the literature, the synthesis of a few optically active P-chiral heterocyclic ligands was described and the transition metal complexes of these $\mathrm{P}(\mathrm{III})$-compounds were used as catalysts mainly in enantioselective hydrogenation reactions $[11,13,16,18,21,28-32]$. There are only a few examples for P-heterocyclic ligands that were used in hydroformylation [5]. Among the transition metal phosphine complexes that can be used as catalyst in hydroformylation, the platinum complexes of P-heterocycles form a class that needs further investigations. Prigle et al. reported the synthesis of the platinum complexes of several 5-, 6and 7-membered P-heterocycles [33,34]. Gouygou et al. synthesized a few bisphosphole platinum-complexes [35]. Recently, our research group contributed to the research of optically active P-stereogenic phosphine oxides, as well as to the synthesis of platinumcomplexes incorporating P-chiral heterocyclic ligands. TADDOL-derivatives and the $\mathrm{Ca}^{2+}$ salts of dibenzoyl- and di-p-toluoyl-tartaric acid were applied as the resolving agents to prepare the enantiomers of the aryl- and alkyl-3-phospholene oxides [36-42], as well as a few six-membered P-heterocyclic phosphine oxides, embracing a 1,2-dihydrophosphinine oxide and a 1,2,3,6-tetrahydrophosphinine oxide $[43,44]$. We have also reported the synthesis of a few racemic and optically active borane and platinum-complexes bearing aryl- and alkyl-3phospholene ligands. The 3-phospholene - platinum complexes were applied as catalysts in the asymmetric hydroformylation of styrene and enantioselectivities up to $29 \%$ were obtained [45-48].

As a continuation of this ongoing research, we wished to proceed with our systematic investigation of the resolution of the 3-phospholene oxides. Another aim of ours was to gain a deeper understanding how the substituents of the 3-phospholene moiety influence the catalytic 
activity of the platinum-complexes incorporating 3-phospholene ligands. In this paper, we report the synthesis and the resolution of the 1-isopropyl-3-methyl-3-phospholene oxide. The 1-isopropyl-3-methyl-3-phospholene-borane and platinum complexes were also prepared in racemic and optically active forms, and the platinum-complexes were tested as catalysts in the hydroformylation of styrene.

\section{Results and discussion}

\subsection{Synthesis and resolution of 1-isopropyl-3-methyl-3-phospholene 1-oxide (3)}

1-Isopropyl-3-methyl-3-phospholene 1-oxide (3) was prepared by extending the synthetic method elaborated for other alkyl- and aryl-3-methyl-3-phospholene oxides [37,47,49]. 1-Hydroxy-3-methyl-3-phospholene 1-oxide (1) was reacted with thionyl chloride to form the corresponding phosphinic chloride (2) which was immediately reacted with isopropylmagnesium bromide to afford 1-isopropyl-3-methyl-3-phospholene 1-oxide (3) in a yield of $49 \%$. As a new compound, the isopropyl-phospholene oxide (3) was characterized by ${ }^{1} \mathrm{H},{ }^{13} \mathrm{C}$ and ${ }^{31} \mathrm{P}$ NMR spectroscopy, as well as HRMS.

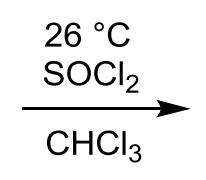

1

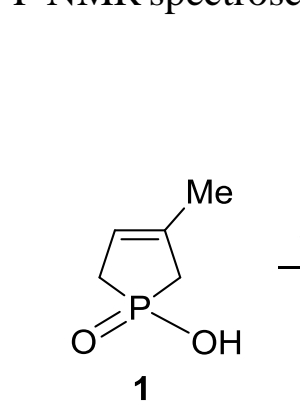

(1) 
A few resolution experiments of isopropyl-phospholene oxide (3) with TADDOLderivatives [(-)-4 and (-)-5] were carried out in a mixture of ethyl acetate and hexane. In these cases, the mixture of the racemic compound (3) and the given resolving agent $[(-)-4$ or $(-)-5]$ was dissolved in hot ethyl acetate, and the corresponding diastereomer precipitated on adding hexane to the reaction mixture.

Applying alcohols, such as methanol, ethanol or isopropanol as the solvent, the racemic compound (3) and the resolving agent $[(-)-4$ or (-)-5] were dissolved in hot alcohols, and the diastereomer appeared by gradually on cooling down the reaction mixture to $26{ }^{\circ} \mathrm{C}$ (Scheme 2).

In all instances, the corresponding diastereomers were separated from the mother liquor by filtration after three hours of crystallization, and they were purified further by two recrystallizations. The composition of the corresponding diastereomers was established by ${ }^{1} \mathrm{H}$ NMR spectroscopy. The enantiomeric mixture of isopropyl-phospholene oxide (3) was recovered from the given diastereomer by column chromatography using silica gel and a 97:3 mixture of dichloromethane and methanol as the eluent. The enantiomeric excess of the isopropyl-phospholene oxide (3) was analyzed by chiral GC.

The results leading to enantiomeric separation of the target molecule $\mathbf{3}$ were summarized in Table 1. Beside the yield and the enantiomeric excess, the resolving capability (S) was also determined. The resolving capability (S) is used to describe the overall efficiency of a given resolution and this value can be calculated as the product of the yield and the enantiomeric excess. 


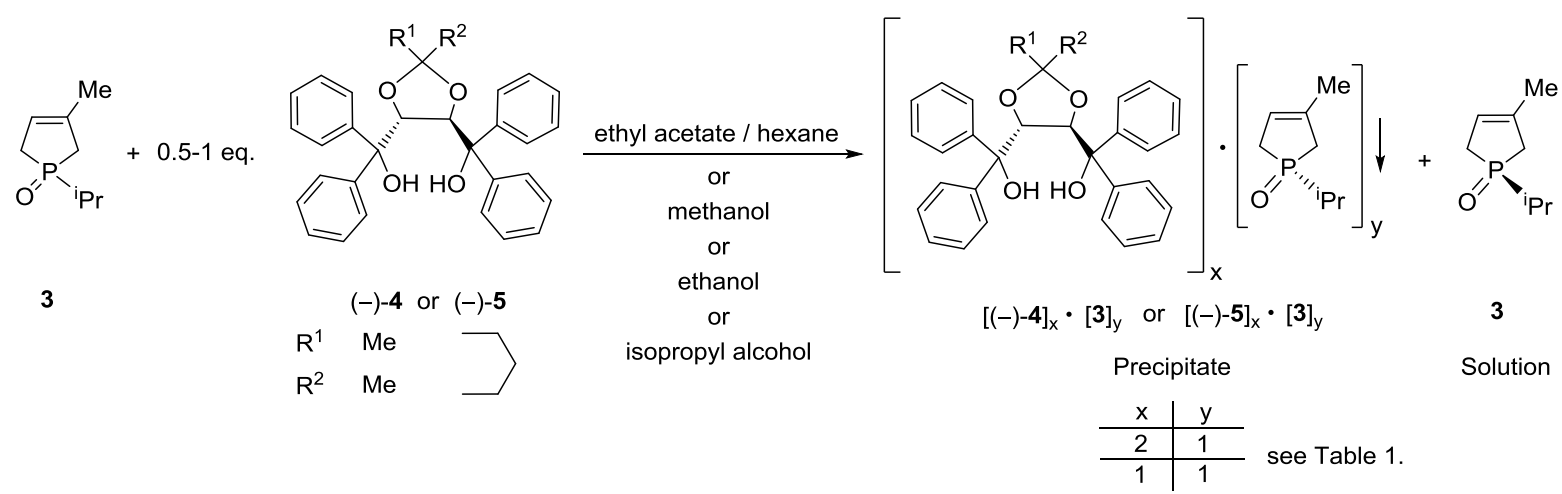

Scheme 2.

Applying TADDOL [(-)-4] as the resolving agent for the enantiomeric separation of 3phospholene oxide $\mathbf{3}$, the crystalline diastereomers were obtained in the cases, when ethyl acetate/hexane or isopropyl alcohol was used (Table 1, Entries 1 and 2). However, the enantiomeric discrimination between the two antipodes of 1-isopropyl-3-phospholene oxide (3) was poor in these instances, as the highest enantiomeric excess and resolving capability values were $6 \%$ and 0.05 , respectively (Table 1, Entry 1). It is noteworthy that no diastereomeric complex was obtained when methanol or ethanol was used as the solvent, and the TADDOL [(-)-4] precipitated exclusively in these instances.

Applying spiro-TADDOL $[(-)-5]$ as the resolving agent, the enatiomeric excess and the resolving capability values were solvent dependent, and the ee was between $57-95 \%$, and the resolving capability fell in the range of 0.34-0.47 (Table 1, Entries 3-6). It is noteworthy that the solvent also influenced which isopropyl-phospholene oxide (3) enantiomer was incorporated into the corresponding diastereomer. $(+)-(R)-1$-Isopropyl-3-phospholene oxide $[(+)-3]$ could be prepared with spiro-TADDOL $[(-)-5]$ in ethyl acetate/hexane or methanol (Table 1, Entries 3 and 4). Carrying out the resolution in ethanol or in isopropyl alcohol led to the other (-)-(S)-1-isopropyl-3-phospholene oxide antipode [(-)-3] (Table 1, Entries 5 and 6). Moreover, the solvent also affected the composition of the diastereomers. A diastereomeric complex incorporating isopropyl-phospholene oxide (3) and spiro-TADDOL [(-)-5] in a 1:1 
ratio was obtained in ethyl acetate/hexane and isopropyl alcohol (Table 1, Entries 3 and 6), and the diastereomer having the composition of $(3) \cdot(\text { spiro-TADDOL })_{2}$ was separated when methanol or ethanol was used as the solvent (Table 1, Entries 4 and 5).

These results indicated that the TADDOL analogue (-)-5 could be used more efficiently for the enantiomeric separation of phosphine oxide $\mathbf{3}$, than the TADDOL [(-)-4] itself (compare Table 1, Entries 1-2 and 3-6).

Table 1. Resolution of 1-isopropyl-3-methyl-3-phospholene 1-oxide (3) with TADDOL derivatives $[(-)-4$ and $(-)-5]$

\begin{tabular}{|c|c|c|c|c|c|c|c|c|}
\hline Entry & Resolving agent & Eq. & Solvents ${ }^{\mathrm{a}, \mathrm{b}}$ & $\begin{array}{l}\text { Diastereomeric } \\
\text { complex }^{c}\end{array}$ & $\begin{array}{l}\text { Yield } \\
(\%)^{\mathrm{d}, \mathrm{g}}\end{array}$ & $\begin{array}{l}\text { ee } \\
(\%)^{e, g}\end{array}$ & $\begin{array}{l}\mathrm{S} \\
(-)^{\mathrm{f}, \mathrm{g}}\end{array}$ & $\begin{array}{l}\text { Abs. } \\
\text { config. }^{\text {h }}\end{array}$ \\
\hline 1 & TADDOL & 0.5 & $2 \times$ EtOAc/10×hexane & (3)(TADDOL) & $\begin{array}{l}(98) \\
\mathbf{8 1}\end{array}$ & $\begin{array}{l}(2) \\
6\end{array}$ & $\begin{array}{l}(0.02) \\
\mathbf{0 . 0 5}\end{array}$ & $(R)$ \\
\hline 2 & TADDOL & 0.5 & $6 \times \mathrm{iPrOH}$ & (3)(TADDOL) & $\begin{array}{l}(81) \\
2^{*}\end{array}$ & $\begin{array}{l}(2) \\
5^{*}\end{array}$ & $\begin{array}{l}(0.02) \\
\mathbf{0 . 0 0 *}\end{array}$ & $(R)$ \\
\hline 3 & spiro-TADDOL & 0.5 & $4 \times$ EtOAc/10×hexane & (3)(spiro-TADDOL) & $\begin{array}{l}(90) \\
\mathbf{6 0}\end{array}$ & $\begin{array}{l}(35) \\
64\end{array}$ & $\begin{array}{l}(0.31) \\
\mathbf{0 . 3 9}\end{array}$ & $(R)$ \\
\hline 4 & spiro-TADDOL & 1 & $6 \times \mathrm{MeOH}$ & $(\mathbf{3})($ spiro-TADDOL) 2 & $\begin{array}{l}(94) \\
\mathbf{6 0}\end{array}$ & $\begin{array}{l}(15) \\
\mathbf{5 7}\end{array}$ & $\begin{array}{l}(0.14) \\
\mathbf{0 . 3 4}\end{array}$ & $(R)$ \\
\hline 5 & spiro-TADDOL & 1 & $6 \times \mathrm{EtOH}$ & $(3)($ spiro-TADDOL) 2 & $\begin{array}{l}(88) \\
\mathbf{5 0}\end{array}$ & $\begin{array}{l}(29) \\
95\end{array}$ & $\begin{array}{l}(0.26) \\
\mathbf{0 . 4 7}\end{array}$ & $(S)$ \\
\hline 6 & spiro-TADDOL & 0.5 & $6 \times{ }_{i} \mathrm{PrOH}$ & (3)(spiro-TADDOL) & $\begin{array}{l}(84) \\
48\end{array}$ & $\begin{array}{l}(38) \\
\mathbf{8 9}\end{array}$ & $\begin{array}{l}(0.32) \\
\mathbf{0 . 4 3}\end{array}$ & $(S)$ \\
\hline
\end{tabular}

a Mixture of solvents for the crystallization [mL of solvent/g of resolving agent].

b Mixture of solvents for the recrystallization(s) [mL of solvent/g of resolving agent].

c The ratio of 3 and (-)-4 or (-)-5 was determined by ${ }^{1} \mathrm{H}$ NMR.

d Based on the half of the racemate 1 that is regarded to be $100 \%$ for each antipode.

e Determined by chiral GC.

f Resolving capability, also known as the Fogassy parameter $(\mathrm{S}=$ Yield $\times$ ee $)$ [50].

g Results obtained after the first crystallization are shown in "( )", while results obtained after two recrystallizations are shown in boldface.

h The absolute configuration of $\mathbf{3}$ was determined by X-Ray analysis and CD spectroscopy.

* Diastereomeric complex was purified with one recrystallization.

The observation that both isopropyl-phospholene oxide antipodes $[(+)-$ and $(-)-3]$ could be prepared with the same resolving agent, (spiro-TADDOL [(-)-5]) in different solvents allowed us to develop a procedure for the preparation of the (+)- and (-)-isopropylphospholene oxide enantiomers [(+)- and (-)-3] from racemic 3 (Scheme 3). The resolution of isopropyl-phospholene oxide $\mathbf{3}$ utilizing spiro-TADDOL [(-)-5] in ethanol afforded 
diastereomer $[(-)-3 \cdot(-)-5]$ that was purified by three recrystallizations to give the $(-)-(S)-1-$ isopropyl-3-phospholene oxide [(-)-3] with an ee of $97 \%$ and in a yield of $45 \%$ after a recovery from the diastereomer by column chromatography.

To prepare $(+)-(R)-1$-isopropyl-3-phospholene oxide $[(+)-3]$, the mother liquors of the crystallization and recrystallizations were combined, and the volatiles were removed to afford a mixture of (+)-3 (ee: $23 \%$ ) and spiro-TADDOL [(-)-5]. To this mixture, a sufficient amount of spiro-TADDOL [(-)-5] was added and the resolution was carried out in methanol to obtain the (+)-isopropyl-phospholene oxide [(+)-3] with an ee of $87 \%$ and in a yield of $40 \%$ after recrystallizations and decomplexation of the corresponding diastereomer $[(+)-\mathbf{3} \cdot(-)-5]$.

Besides the methanol, the mixture of ethyl acetate and hexane was also a suitable solvent combination to prepare the $(+)-(R)-1$-isopropyl-3-phospholene oxide [(+)-3] by resolution with spiro-TADDOL $[(-)-5]$, as it was indicated by the preliminary experiments (Table 1 , Entries 3 and 4). Moreover, considering the resolving capability values, the application of ethyl acetate/hexane seemed to be more advantageous than methanol (Compare Table 1, Entries 3 and 4). However, the purity of the corresponding diastereomer $[(+)-3 \cdot(-)-5]$ could not be improved by recrystallizations from ethyl acetate/hexane with the maximum diastereomeric excess $(d e)$ was $64 \%$. This phenomenon may be explained by the fact that the $(+)-3 \cdot(-)-5$ diastereomer has a eutectic composition at the de of $64 \%$, which hinders the purification of this diastereomer. As a consequence, methanol was chosen for the preparation of (+)-(R)-1-isopropyl-3-phospholene oxide [(+)-3] by resolution, as it was detailed above. 


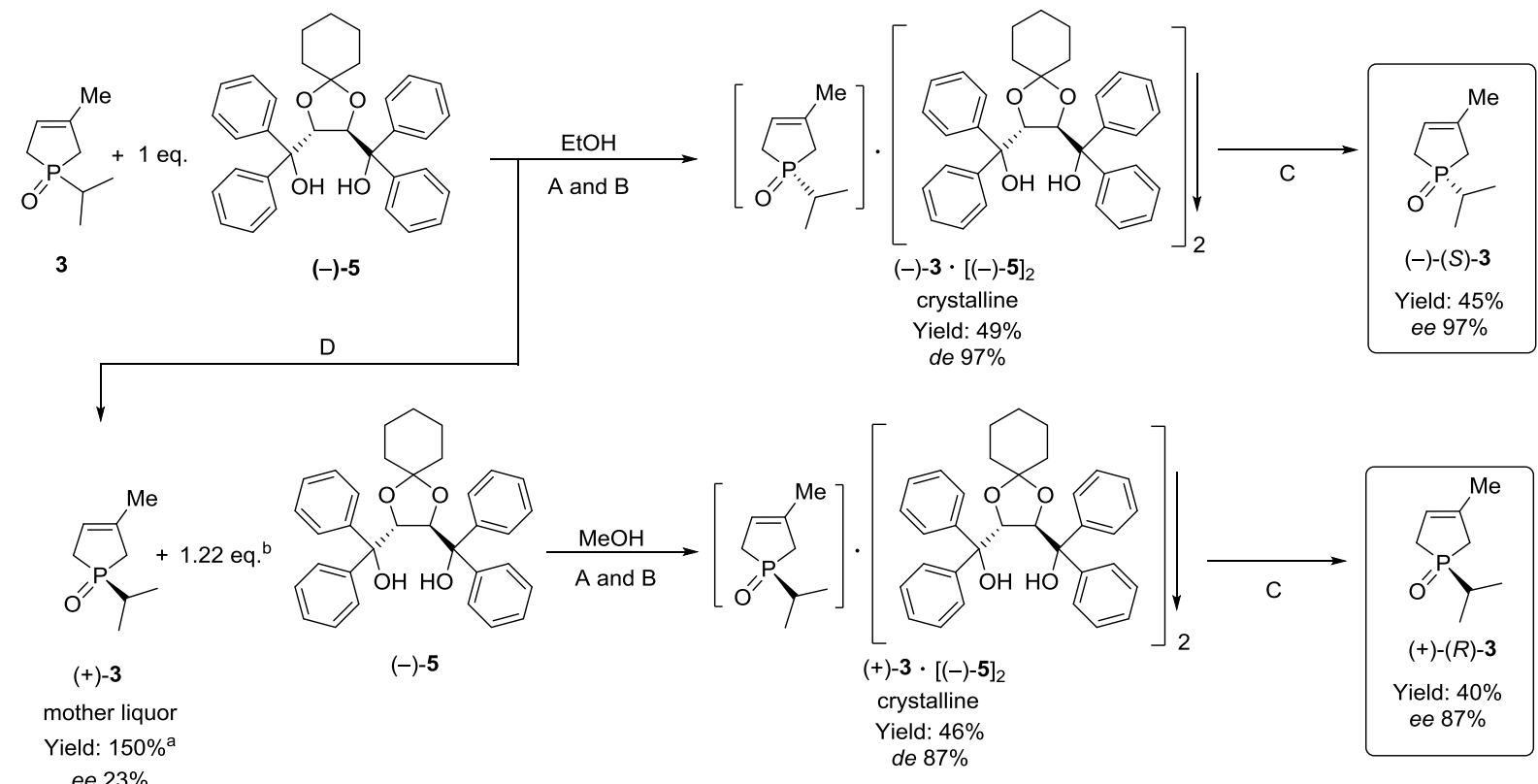

A: crystallization; B: recrystallization; C: column cromatography; D: evaporation

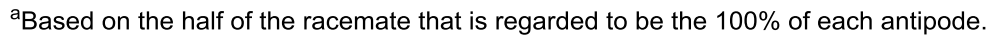

${ }^{\mathrm{b}}$ The residue of the mother liquor contained 0.69 eq. of $(-)-5,0.53$ eq. of $(-)-5$ was added.

Scheme 3 .

Single crystal X-ray structure determination from a proper sample obtained from recrystallizations (Table 1, Entry 5), revealed as the most conspicuous feature, also the 1:2 composition of phospholene oxide (-)-3 and spiro-TADDOL (-)-5 in the asymmetric unit of the crystal (Fig. 1). 


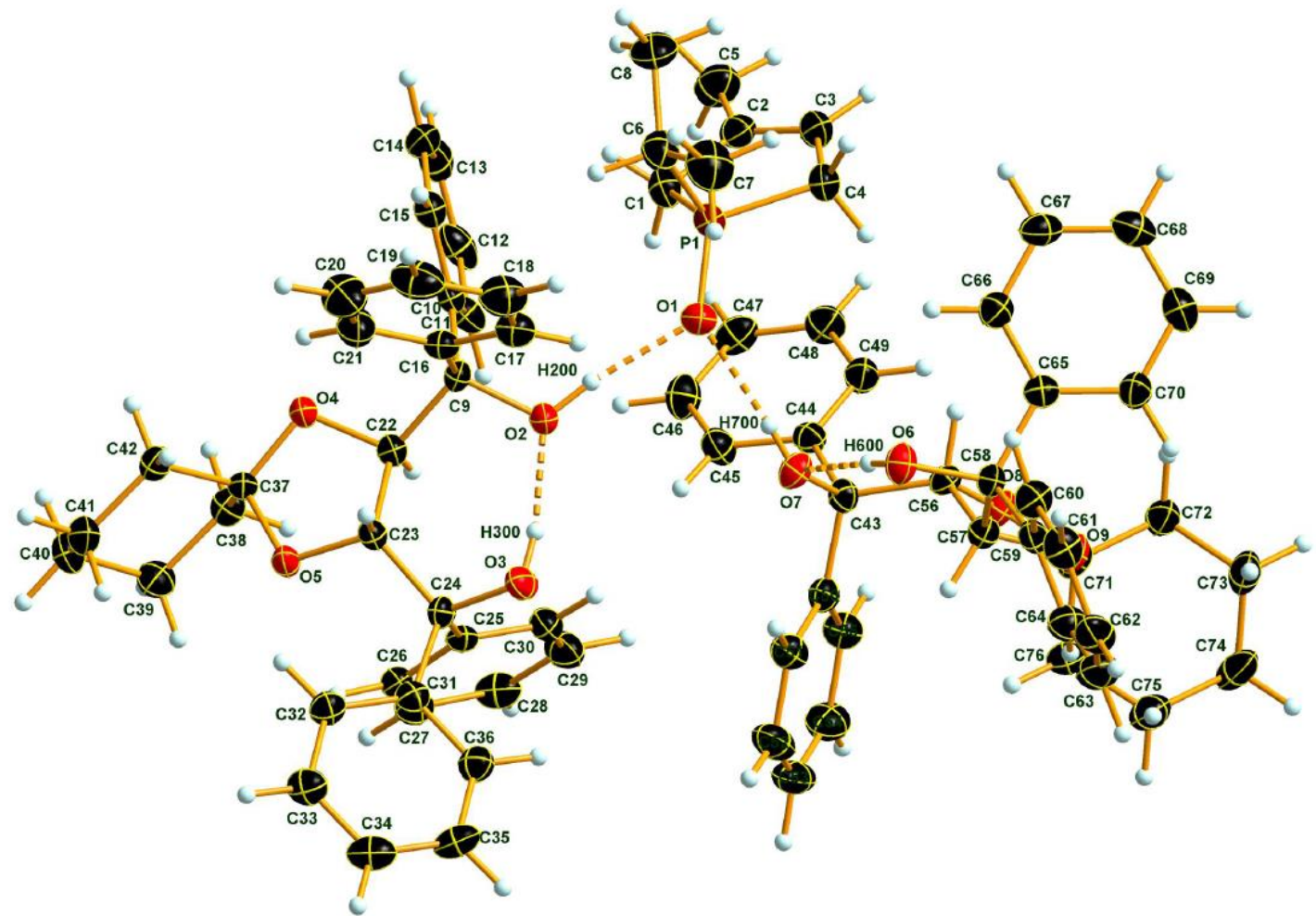

Fig. 1. Atomic displacement representation (50\% probability) of the diastereomeric complex incorporating (-)-3 and (-)-5 in a ratio of 1:2 in the asymmetric unit with atomic numbering and indication of the "classical" $\mathrm{O}-\mathrm{H} . . . \mathrm{O}$ type $\mathrm{H}$-bridges (in broken lines).

The appearance of two independent hosts in the crystallographic asymmetric units is a frequently observed stoichiometry feature in this line of experiments. Two examples from our recent studies with 2:2 resolving host - target guest ratio are the 1-butyl-3-methyl-3phospholene oxide [40] and the 1-propoxy-3-methyl-3-phospholene oxide [41] guest containing crystal structures. This directs attention to the altered stoichiometry from the frequently observed 2:2 host/guest ratio. Lately, we expounded the idea of competitive resolution [42], where the 2:2 ratio is violated, such that the inclusion of the solvent $i$-PrOH instead of a second phospholene occurred yielding a 1:1:2 guest/solvent/hosts stoichiometry. Here we have another case as there is only one (-)-3 guest embedded between two (-)-5 hosts. It is apparent that the guest is primarily anchored by the H-bridges donated from each 
(-)-5 molecules. Classical H-bonding dimensions ( $c f$. Table 2) are all well defined and comply with expectations. The H-bonding pattern retains the well-known internal H-bridge structure of the resolving tool, providing a single-donor function only for $\mathrm{H}$-bridging from each spiro-TADDOL [(-)-5] host molecules. The double acceptor role of the 3-phospholene oxide [(-)-3] ideally uses both lone pair of the $\mathrm{O}$ atom. Nevertheless, it is not the classical Hbridge scheme that delivers surprise. The (-)-3 guest molecule boasts with an unusually large number (11) of short $\mathrm{C}-\mathrm{H}$...O contacts to the two [(-)-5] molecules of the stoichiometric entity (the crystallographic asymmetric unit). In other words, all but one of these contacts are of intramolecular (correctly intra-associate) type, 10 out of 11 . A closer scrutiny is thus warranted. The first step to go ahead is to "normalize" the $\mathrm{C}-\mathrm{H}$ bond lengths to the "industry - standard” $1.08 \AA$ internuclear distance. For comparison Table 2A lists these for the classical $\mathrm{H}$-bridges, too, while Table $2 \mathrm{~B}$ for the less trivial $\mathrm{C}-\mathrm{H}$...O ones as well. The emerging pattern is also interesting, as almost half of the non-trivial contacts are then eliminated, 5 or 6 out of 11 . These fail to qualify as $\mathrm{H}$-bridge as their $\mathrm{D}-\mathrm{H}$...A angles got under $100^{\circ}$. This is not so surprising, as the classical $\mathrm{H}$-bridges are nearly linear, so the $\mathrm{C}-\mathrm{H}$ bond increasing will only improve on their geometry. In contrast, the $\mathrm{C}-\mathrm{H}$...O contacts are more bent, and in cases where the control angle gets under $100^{\circ}$ the analysing program drops them from the list. 
Table 2. Hydrogen Bonds $\left(\AA \AA,^{\circ}\right)$ for (-)-1-isopropyl-3-methyl-3-phospholene oxide [(-)-3]. The rows beneath each contact (marked "Normalized") indicate geometry after alteration the $\mathrm{D}-\mathrm{H}$ bond lengths to generally accepted standard distances as shown. 2A) Classical $\mathrm{O}-\mathrm{H}$...O H-bridges; 2B) $\mathrm{C}-\mathrm{H}$...contact distances $2 \mathrm{~A}$ )

\begin{tabular}{|c|c|c|c|c|c|}
\hline \multicolumn{6}{|l|}{ 2A) } \\
\hline $\mathrm{D}-\mathrm{H} \ldots \mathrm{A}$ & $\mathrm{D}-\mathrm{H}(\AA)$ & H...А $(\AA)$ & D...A $(\AA)$ & $\mathrm{D}-\mathrm{H} \ldots \mathrm{A}\left({ }^{\circ}\right)$ & Ser. No. \\
\hline $\mathrm{O} 2$-- H200 .. O1 & $0.89(3)$ & $1.85(3)$ & $2.727(2)$ & 172(3) & 1 \\
\hline Normalized & 0.98 & 1.75 & $2.727(2)$ & 172 & \\
\hline $\mathrm{O} 3$-- H300 .. O2 & $0.86(3)$ & $1.85(3)$ & $2.705(3)$ & $171(2)$ & 2 \\
\hline Normalized & 0.98 & 1.73 & $2.705(3)$ & 170 & \\
\hline O6 -- H600 .. O7 & $0.85(3)$ & $1.82(3)$ & $2.666(3)$ & $175(3)$ & 3 \\
\hline Normalized & 0.98 & 1.68 & $2.666(3)$ & 175 & \\
\hline O7 -- H700 .. O1 & $0.77(3)$ & $1.90(3)$ & $2.671(2)$ & $176(4)$ & 4 \\
\hline Normalized & 0.98 & 1.69 & $2.671(2)$ & 175 & \\
\hline \multicolumn{6}{|l|}{ 2B) } \\
\hline $\mathrm{C} 5$-- $\mathrm{H} 5 \mathrm{C} . . \mathrm{O}_{i}$ & 0.99 & 2.50 & $3.307(3)$ & 138 & 1 \\
\hline Normalized & 1.08 & 2.44 & $3.307(3)$ & 136 & \\
\hline C17 -- H17 .. O2 & 0.99 & 2.43 & $2.791(3)$ & 100 & 2 \\
\hline- & - & - & - & - & \\
\hline $\mathrm{C} 21$-- H21 .. O4 & 0.96 & 2.31 & $2.967(3)$ & 126 & 3 \\
\hline Normalized & 1.08 & 2.23 & $2.967(3)$ & 123 & \\
\hline C26 -- H26 .. O5 & 0.99 & 2.55 & $3.026(3)$ & 109 & 4 \\
\hline Normalized & 1.08 & 2.52 & $3.026(3)$ & 107 & \\
\hline C30 -- H30 .. O3 & 0.99 & 2.42 & $2.792(3)$ & 101 & 5 \\
\hline- & - & - & - & - & \\
\hline C 32 -- H32 .. O5 & 0.96 & 2.24 & $2.872(3)$ & 122 & 6 \\
\hline Normalized & 1.08 & 2.18 & $2.872(3)$ & 120 & \\
\hline C49 -- H49 .. O8 & 0.96 & 2.51 & $3.031(3)$ & 114 & 7 \\
\hline Normalized & 1.08 & 2.46 & $3.031(3)$ & 111 & \\
\hline C51 -- H51 .. O7 & 0.96 & 2.38 & $2.729(3)$ & 101 & 8 \\
\hline- & - & - & - & - & \\
\hline C64 -- H64 .. O9 & 1.03 & 2.33 & $2.935(3)$ & 116 & 9 \\
\hline Normalized & 1.08 & 2.31 & $2.935(3)$ & 115 & \\
\hline C66 -- H66 .. O6 & 0.95 & 2.41 & $2.768(3)$ & 102 & 10 \\
\hline- & - & - & - & - & \\
\hline C70 -- H70 .. O9 & 1.00 & 2.58 & $2.948(3)$ & 101 & 11 \\
\hline Normalized & 1.08 & 2.57 & $2.948(3)$ & 100 & \\
\hline
\end{tabular}

Transformation applied: $\mathrm{i}=1+\mathrm{x}, \mathrm{y}, \mathrm{z}$.

Nevertheless, this does not mean that there cannot be other, non- $H$-bridge interactions between such entities. There are, for example, indications that some 
C - H.... $\mathrm{C}_{\text {aryl }}$ type of short contacts exist. We could just stop here and conclude that the (-)-3 guest is so tightly bound to its two (-)-5 molecules in their lap that the host conformations may not permit inclusion of a second (-)-3 molecule. A full interaction mapping was attempted by the aid of program Mercury [51]. The chemical functions defined for the mapping were the $\mathrm{OH}$, aryl- $\mathrm{CH}$, and methyl groups. These were used as target interactions in the mapping program, and the results are shown in Fig. 2. The "hot spots" can be seen well, where interactions of the given kind are the most concentrated.

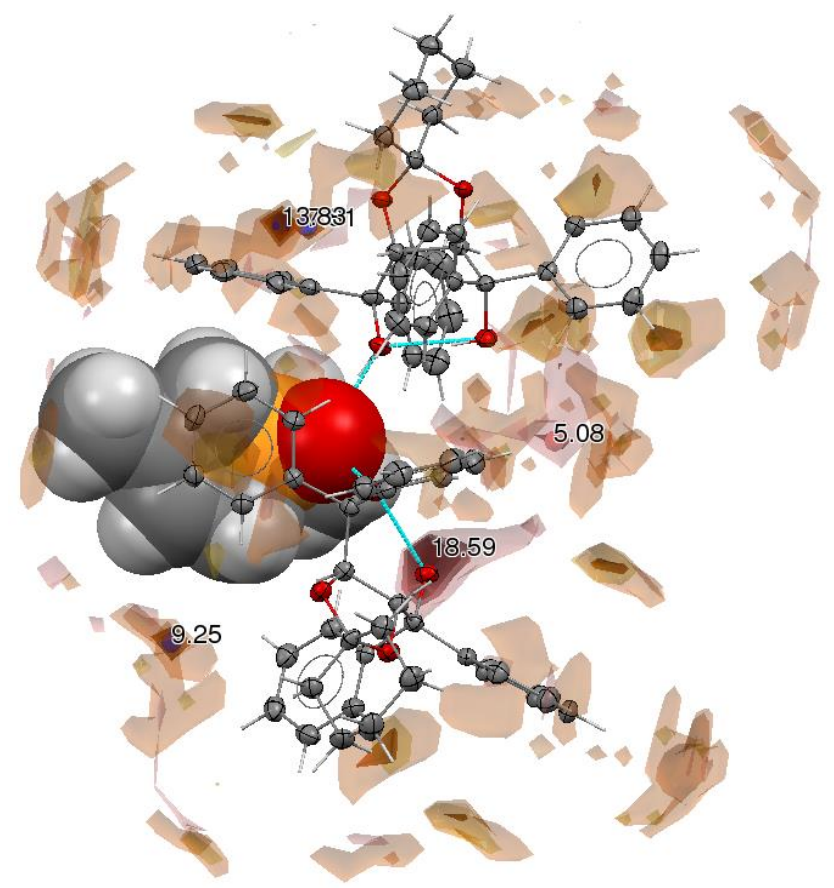

Fig. 2. A full interaction mapping [51] of the asymmetric unit containing (-)-3 and (-)-5 in a ratio of 1:2 in the crystal with (-)-3 in space filling representation. Light contours correspond to at least two, while darker more than six contributors. Numbers represent "hot spots" i.e. the maximum interaction directions.

It is clear that the dominant hydrophilic interactions roughly match the observed "hot spots" in Fig. 2. A further support for the tight encapsulation of (-)-3 comes from the UNI intermolecular potential force filed (FF) type calculation [52,53]. 


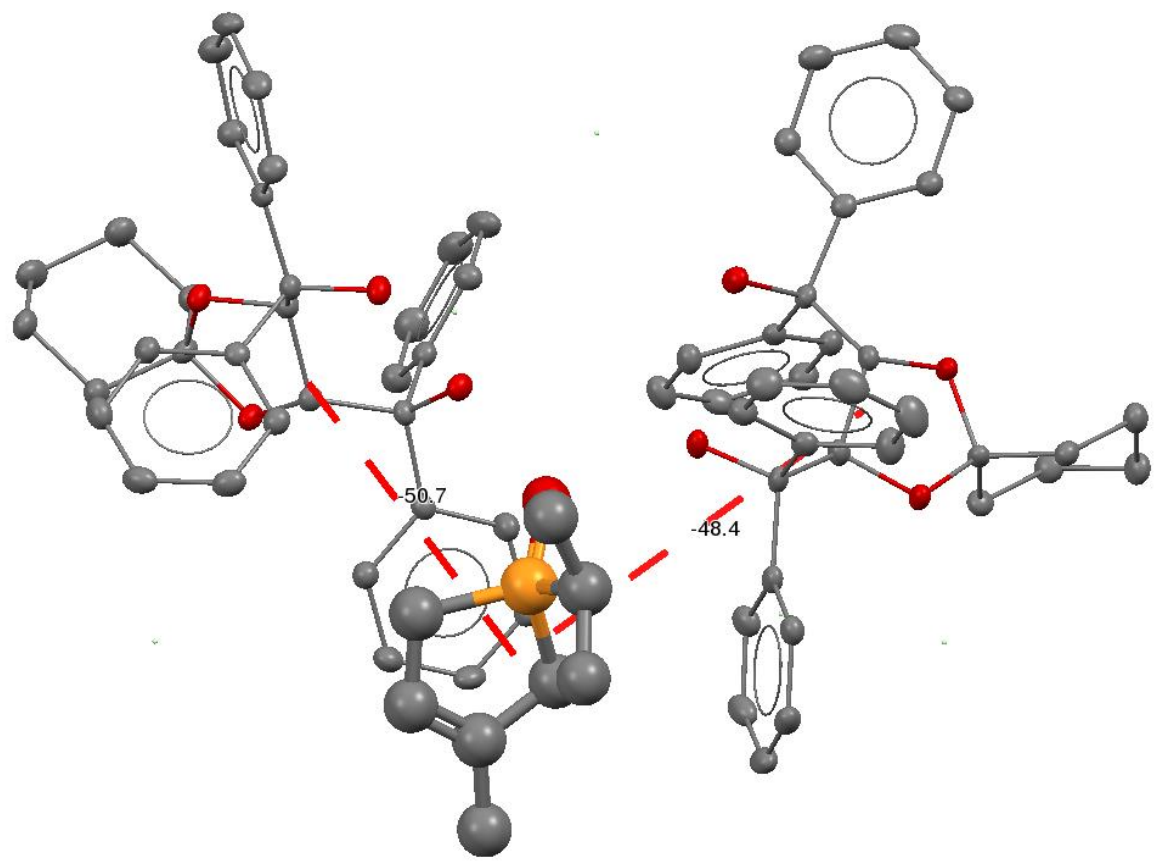

Fig. 3. UNI intermolecular potential calculation results [52,53] as implemented in Mercury [51] show the two largest lattice contribution in red broken lines to molecule (-)-3 from each independent (-)-5 molecule with -50.7 and $-48.4 \mathrm{~kJ} / \mathrm{mol}$, respectively.

The graphical view (Fig. 3) of the results underlines that the two strongest interactions are between (-)-3 and each of the independent (-)-5 molecules in the asymmetric unit, with -50.7 and $-48.4 \mathrm{~kJ} / \mathrm{mol}$. Inter-fragment energies are [(-)-3 and (-)-5 $\mathrm{I}]:-50.7 \mathrm{~kJ} / \mathrm{mol},[(-)-3$ and (-)-5 $\left.5_{\mathrm{II}}\right]:-48.4 \mathrm{~kJ} / \mathrm{mol},\left[(-)-5_{\mathrm{I}}\right.$ and $\left.(-)-5_{\mathrm{II}}\right]:-36.4 \mathrm{~kJ} / \mathrm{mol}$. A considerable portion $(-135.5 \mathrm{~kJ} / \mathrm{mol})$ of the total of $-484 \mathrm{~kJ} / \mathrm{mol}$ packing energy is thus in the interactions between these three molecules of the asymmetric unit. Subsequently, semi-empirical series of calculations were also used to assess feasibility of the FF results. These were done by using modified PM6 [54] Hamiltonians suggested by Korth (PM6-DH+) [55] and as implemented in MOPAC012 [56,57]. The aim was to derive and estimate independently the binding energy of $(-)-3$ to the two molecules of (-)-5 as in the lattice of the associate crystal. The proposed strategy for this goal is to use the PM6-DH+ procedure to optimize the geometry of each component separately and also to obtain heats of formations for each of them. As FF 
calculations indicated essential attraction between the two independent $(-)-5$ molecules a change was made such that the geometries were optimized and heat of formation was calculated for this assembly of the two spiro-TADDOL molecules. Then the content of the asymmetric unit is optimized and the heats of formation are obtained. The binding (or

intermolecular interaction) energy is then given by

$\Delta \mathrm{H}_{\mathrm{B}}=\Delta \mathrm{H}_{\mathrm{F}}\left[(-)-3-(-)-5_{\mathrm{I}}-(-)-5_{\mathrm{II}}\right]-\Delta \mathrm{H}_{\mathrm{F}}[(-)-3]-\Delta \mathrm{H}_{\mathrm{F}}\left[(-)-5_{\mathrm{I}} /(-)-5_{\mathrm{II}}\right]$. Heats of formations components were $-1596,-409,-1062 \mathrm{~kJ} / \mathrm{mol}$, for $\left[(-)-3-(-)-5_{I}-(-)-5_{I I}\right],[(-)-3]$, and for the $\left[(-)-5_{\mathrm{I}} /(-)-5_{\mathrm{II}}\right]$ assembly. The resulting binding energy of $-125 \mathrm{~kJ} / \mathrm{mol}$ compares well with those obtained from the FF computations. During this procedure basic geometry features, such as conservation of H-bridges, etc., were checked and all major features were retained in the resulting models. All models converged using default gradients for optimization. A modest internal calibration was also provided as $\Delta \mathrm{H}_{\mathrm{F}}\left[(-)-5_{\mathrm{I}}\right]$ and $\Delta \mathrm{H}_{\mathrm{F}}\left[(-)-5_{\mathrm{II}}\right]$ may be expected to be identical. These were -480 and $-488 \mathrm{~kJ} / \mathrm{mol}\left[(-)-5_{\mathrm{I}}\right]$ and [(-)-5 $\left.5_{\mathrm{II}}\right]$, respectively. The less than $2 \%$ difference between the $\Delta \mathrm{H}_{\mathrm{F}}$ values would probably be a too optimistic estimate of the uncertainty. Nevertheless, the important message is that both approaches confirm and similarly quantify the energy background of the geometry conditions of binding in the crystal structure, in spite of the more or less differing starting geometries.

Besides the TADDOL-derivatives [(-)-4 and (-)-5], the resolution of 1-isopropyl-3methyl-3-phospholene 1-oxide (3) was also attempted with the acidic $\mathrm{Ca}^{2+}$ salts of (-)-O,O'dibenzoyl- or (-)- $O, O^{\prime}$-di-p-toluoyl-(2R,3R)-tartaric acid [Ca(H-DBTA $)_{2}(-)-6$ or $\mathrm{Ca}(\mathrm{H}-$ DPTTA $\left.)_{2}(-)-7\right]$. The $\mathrm{Ca}(\mathrm{H}-\mathrm{DBTA})_{2}[(-)-6]$ was prepared in advance as described earlier [38], whereas the $\mathrm{Ca}(\mathrm{H}-\mathrm{DPTTA})_{2}[(-)-7]$ was always formed in situ in the reaction of $(-)-O, O^{\prime}$-di-p-toluoyl-(2R,3R)-tartaric acid and $\mathrm{CaO}$ in the mixture of ethanol and water. 
During the resolution experiments, the given solution of the isopropyl-phospholene oxide (3) was added to the hot ethanolic solution of $\mathrm{Ca}(\mathrm{H}-\mathrm{DBTA})_{2}(-)-6$ or $\mathrm{Ca}(\mathrm{H}-\mathrm{DPTTA})_{2}(-)-7$. The diastereomers appeared after cooling down the reaction mixture gradually to $26{ }^{\circ} \mathrm{C}$ (Scheme 4). The crystals were filtered off after $24 \mathrm{~h}$ of crystallization and were purified further by digestion (i.e. by stirring the diastereomers in the corresponding solvent or solvent mixture at $\left.26{ }^{\circ} \mathrm{C}\right)$. The composition of the diastereomers was determined by ${ }^{1} \mathrm{H}$ NMR spectroscopy. To obtain the enantiomeric mixture of isopropyl-phospholene oxide (3), the crystalline diastereomer was treated with $10 \%$ aqueous ammonia and the solution was extracted with dichloromethane. The enantiomeric excess of phospholene oxide 3 was determined by chiral GC. The results are summarized in Table 3.

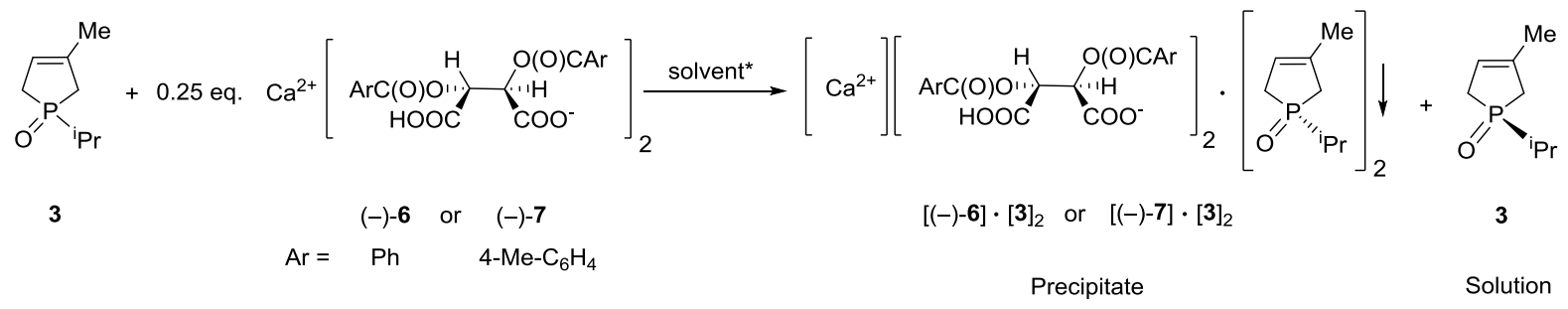

${ }^{*}$ See Table 3

\section{Scheme 4.}

Using $\mathrm{Ca}(\mathrm{H}-\mathrm{DBTA})_{2}[(-)-6]$ as the resolving agent, the enantiomeric excess of the (+)$(R)$-1-isopropyl-3-phospholene oxide $[(+)-3]$ fell in the range of $36-48 \%$ after one recrystallization, and the corresponding diastereomers were obtained in low yields meaning resolving capability values of 0.02-0.03 (Table 3, Entries 1-3).

When $\mathrm{Ca}(\mathrm{H}-\mathrm{DPTTA})_{2}[(-)-7]$ was applied as the resolving agent, the enantiomeric excess of phospholene oxide 3 was in the range of $85-92 \%$ (Table 3, Entries 4-6). Despite the promising ee values, the yield of the corresponding diastereomers remained low in all instances, when $\mathrm{Ca}(\mathrm{H}-\mathrm{DPTTA})_{2}[(-)-7]$ was applied and the corresponding resolving 
capability values fell in the range of 0.01-0.09 (Table 3, Entries 4-6). It is noteworthy that the solvent influenced which isopropyl-phospholene oxide antipode (3) was incorporated into the corresponding diastereomer. Applying $\mathrm{Ca}(\mathrm{H}-\mathrm{DPTTA})_{2}[(-)-7]$, the (-)-(S)-1-isopropyl-3phospholene oxide [(-)-3] could be prepared in a mixture of ethanol and water or in a mixture of ethanol, ethyl acetate and water (Table 3, Entries 4 and 5), while the (+)-(R)-1-isopropyl-3phospholene oxide [(+)-3] could be obtained in a mixture of ethanol, acetonitrile and water (Table 3, Entry 6).

The results shown in Table 3 indicated that the overall efficiency of resolutions with $\mathrm{Ca}(\mathrm{H}-\mathrm{DBTA})_{2}(-)-6$ or $\mathrm{Ca}(\mathrm{H}-\mathrm{DPTTA})_{2}(-)-7$ was considerably lower than those obtained with spiro-TADDOL (-)-5 which agent was proved to be the best for the enantiomeric separation of 1-isopropyl-3-methyl-3-phospholene 1-oxide (3) in our study.

Table 3. Resolution of 1-isopropyl-3-methyl-3-phospholene 1-oxide (3) with 0.25 equivalent of $\mathrm{Ca}(\mathrm{H}-\mathrm{DBTA})_{2}[(-)-6]$ or $\mathrm{Ca}(\mathrm{H}-\mathrm{DPTTA})_{2}[(-)-7]$

\begin{tabular}{|c|c|c|c|c|c|c|c|c|}
\hline Entry & Resolving agent & Eq. & Solvents & $\begin{array}{l}\text { Diastereomeric } \\
\text { complex }^{c}\end{array}$ & $\begin{array}{l}\text { Yield } \\
(\%)^{\mathrm{d}, \mathrm{g}}\end{array}$ & $\begin{array}{l}\text { ee } \\
(\%)^{\mathrm{e}, \mathrm{g}}\end{array}$ & $\begin{array}{l}S \\
(-)^{f, g}\end{array}$ & $\begin{array}{l}\text { Abs. } \\
\text { config. }\end{array}$ \\
\hline 1 & $\mathrm{Ca}(\mathrm{H}-\mathrm{DBTA})_{2}$ & 0.25 & $6 \times \mathrm{EtOH}^{\mathrm{a}, \mathrm{b}}$ & $\mathrm{Ca}(\mathbf{3})_{2}(\mathrm{H}-\mathrm{DBTA})_{2}$ & $\begin{array}{l}(33) \\
8^{*}\end{array}$ & $\begin{array}{l}(35) \\
4^{*}\end{array}$ & $\begin{array}{l}(0.11) \\
\mathbf{0 . 0 3}^{*}\end{array}$ & $(R)$ \\
\hline 2 & $\mathrm{Ca}(\mathrm{H}-\mathrm{DBTA})_{2}$ & 0.25 & $\begin{array}{l}3 \times \mathrm{EtOH}^{\prime} 3 \times \mathrm{EtOAc}^{\mathrm{a}} \\
1 \times \mathrm{EtOH} / 1 \times \mathrm{EtOAc}^{\mathrm{b}}\end{array}$ & $\mathrm{Ca}(\mathbf{3})_{2}(\mathrm{H}-\mathrm{DBTA})_{2}$ & $\begin{array}{l}(15) \\
4^{*}\end{array}$ & $\begin{array}{l}(24) \\
36^{*}\end{array}$ & $\begin{array}{l}(0.04) \\
\mathbf{0 . 0 2} *\end{array}$ & $(R)$ \\
\hline 3 & $\mathrm{Ca}(\mathrm{H}-\mathrm{DBTA})_{2}$ & 0.25 & $3 \times \mathrm{EtOH} / 3 \times \mathrm{MeCN}^{\mathrm{a}, \mathrm{b}}$ & $\mathrm{Ca}(\mathbf{3})_{2}(\mathrm{H}-\mathrm{DBTA})_{2}$ & $\begin{array}{l}(49) \\
5^{*}\end{array}$ & $\begin{array}{l}(44) \\
48^{*}\end{array}$ & $\begin{array}{l}(0.22) \\
\mathbf{0 . 0 2 *}\end{array}$ & $(R)$ \\
\hline 4 & $\mathrm{Ca}(\mathrm{H}-\mathrm{DPTTA})_{2}$ & 0.25 & $6 \times \mathrm{EtOH} / 5 \% \mathrm{H}_{2} \mathrm{O}^{\mathrm{a}, \mathrm{b}}$ & $\mathrm{Ca}(\mathbf{3})_{2}(\mathrm{H}-\mathrm{DPTTA})_{2}$ & $\begin{array}{l}(50) \\
1\end{array}$ & $\begin{array}{l}\text { (4) } \\
90\end{array}$ & $\begin{array}{l}(0.02) \\
\mathbf{0 . 0 1}\end{array}$ & $(S)$ \\
\hline 5 & $\mathrm{Ca}(\mathrm{H}-\mathrm{DPTTA})_{2}$ & 0.25 & $\begin{array}{l}3 \times \mathrm{EtOH} / 3 \times \mathrm{EtOAc} / 10 \% \mathrm{H}_{2} \mathrm{O}^{\mathrm{a}} \\
1 \times \mathrm{EtOH} / 1 \times \mathrm{EtOAc}^{\mathrm{b}}\end{array}$ & $\mathrm{Ca}(\mathbf{3})_{2}(\mathrm{H}-\mathrm{DPTTA})_{2}$ & $\begin{array}{l}(45) \\
10\end{array}$ & $\begin{array}{l}(46) \\
92\end{array}$ & $\begin{array}{l}(0.21) \\
\mathbf{0 . 0 9}\end{array}$ & $(S)$ \\
\hline 6 & $\mathrm{Ca}(\mathrm{H}-\mathrm{DPTTA})_{2}$ & 0.25 & $\begin{array}{l}3 \times \mathrm{EtOH} / 3 \times \mathrm{MeCN} / 10 \% \mathrm{H}_{2} \mathrm{O}^{\mathrm{a}} \\
1 \times \mathrm{EtOH} / 1 \times \mathrm{MeCN}^{\mathrm{b}}\end{array}$ & $\mathrm{Ca}(\mathbf{3})_{2}(\mathrm{H}-\mathrm{DPTTA})_{2}$ & $\mathbf{2}^{(44)}$ & $\begin{array}{l}(41) \\
\mathbf{8 5}\end{array}$ & $\begin{array}{l}(0.18) \\
\mathbf{0 . 0 2}\end{array}$ & $(R)$ \\
\hline
\end{tabular}

\footnotetext{
${ }^{\mathrm{a}}$ Mixture of solvents for the crystallization [mL of solvent/g of resolving agent].

b Mixture of solvents for the recrystallization(s) [mL of solvent/g of resolving agent].

c The ratio of $\mathbf{3}$ and (-)-4 or (-)-5 was determined by ${ }^{1} \mathrm{H}$ NMR.

d Based on the half of the racemate 1 that is regarded to be $100 \%$ for each antipode.

e Determined by chiral GC.

f Resolving capability, also known as the Fogassy parameter ( $\mathrm{S}=$ Yield $\times$ ee) [50].

g Results obtained after the first crystallization are shown in "( )", while results obtained after two recrystallizations are shown in boldface.

$\mathrm{h}$ The absolute configuration of $\mathbf{3}$ was determined by X-Ray analysis and CD spectroscopy.

* Diastereomeric complex was purified with one recrystallization.
} 


\subsection{Spectra of the optically active 1-isopropyl-3-methyl-3-phospholene 1-oxide (3)}

The absolute configuration of the title compound (3) was determined by combined spectroscopic and theoretical investigations. To compute the spectra of the title compound, foremost, a molecular mechanical (MM) conformation analysis was performed for the molecule, and 12 stable conformers were found, which lie at most at $10 \mathrm{~kJ} / \mathrm{mol}$ above the lowest energy one. For each of these conformers, the geometry was further optimized at the density functional theory (DFT) level, and accurate conformational energies were computed using the direct random phase approximation (dRPA) approach. Three low-energy conformers were found differing in the orientation of the isopropyl group, two of them are practically isoenergetic, whereas the third one lies at around $1.3 \mathrm{~kJ} / \mathrm{mol}$ below the two others. The optimized structure and geometrical parameters for the most stable conformer are presented in Fig. 4.

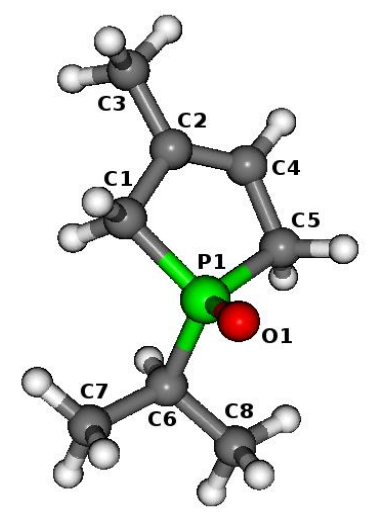

Fig. 4. DFT-optimized geometry for the most stable conformer of phospholene oxide $\mathbf{3}$ with the randomly selected $(S)$ configuration. Characteristic bond lengths (in $\AA$ ) and angles (in degree) are as follows: P1-O1 1.492, P1-C1 1.838, C1-C2 1.503, C2-C3 1.490, C2-C4 1.335, C4-C5 1.496, C5-P1 1.839, P1-C6 1.835, C6-C7 1.525, C6-C8 1.525; O1-P1-C6 113, C1-P1C5 95, C1-P1-C6 106, O1-P1-C1 117, O1-P1-C5 117, C5-P1-C6 106, C7-C6-C8 111, C1-C2C4 116, C4-C5-P1 104; O1-P1-C6-C7 61, O1-P1-C6-C8 -61, P1-C1-C2-C4 -9, C3-C2-C4-C5 179. 
The excitation energies, as well as oscillator and rotator strengths for all the three conformers were computed at the time-dependent DFT (TD-DFT) level. The theoretical UV absorption and CD curves for each conformer were obtained as superpositions of Gaussian functions placed at the wavelengths of the computed transitions with heights proportional to the corresponding calculated oscillator (rotator) strengths. The spectra of the conformers were Boltzmann-weighted. The averaged spectra were normalized so that the height of the highest peak was identical to that of the experimental spectra and were not shifted. The theoretical and experimental spectra are presented in Fig 5.

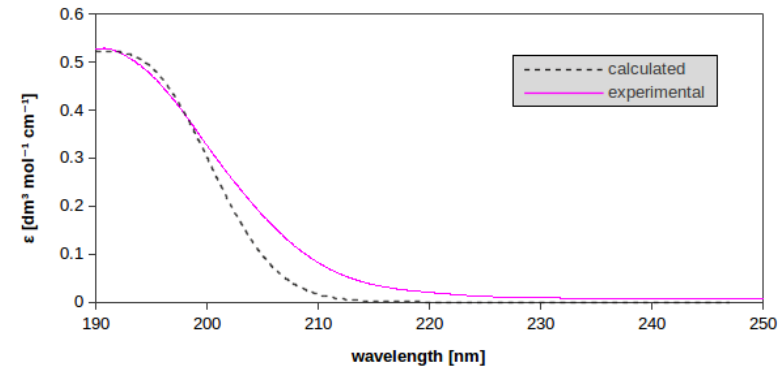

a

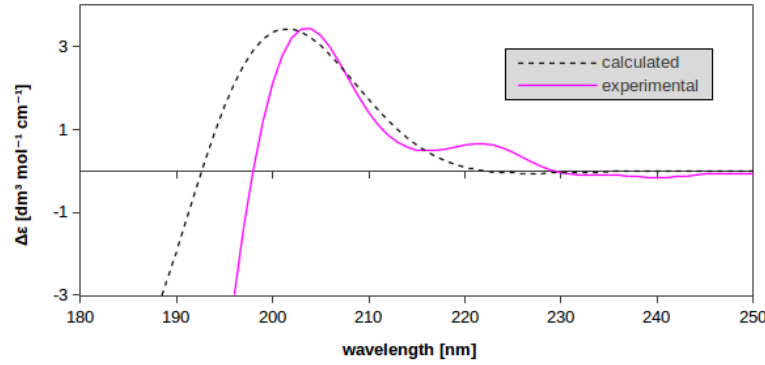

b

Fig. 5. The calculated (dashed line) UV absorption (a) and CD (b) spectra of $(S)$-3 with the corresponding measured spectra (solid line).

Considering the similarity of the measured and calculated absorption spectra of compound 3, we can conclude that the selected theoretical methods are adequate. The structure of the measured and calculated CD spectra is rather similar. The signs of the dominant peaks in the two spectra are identical, and their positions are close to each other. Consequently, the absolute configuration of the enantiomer obtained by the resolution (Table 1, Entry 5) is also $(S)$, like the configuration of the enantiomer considered in the calculations. 


\subsection{Synthesis of 1-isopropyl-3-methyl-3-phospholene borane and platinum complexes}

\section{(9 and 10)}

First, the racemic and optically active isopropyl-phospholene oxides [3 and (S)-3] were deoxygenated with trichlorosilane in separate reactions to obtain the corresponding racemic and optically active isopropyl-phospholenes [8 and (R)-8] (Schemes 5 and 6). Deoxygenations with trichlorosilane are known to proceed with retention of configuration of the P-stereogenic center in case of optically active phosphine oxides. [58].

The racemic and optically active 3-phospholenes $[\mathbf{8}$ and $(R)-8]$ so obtained were immediately reacted with dimethylsulfide-borane to furnish the corresponding isopropylphospholene-boranes [9 and (R)-9] (Schemes 5 and 6). Beside the synthetic interest, the importance of phosphine boranes is demonstrated by the fact that they may be regarded as protected phosphines, from which the corresponding $\mathrm{P}(\mathrm{III})$-compounds can be liberated by treatment with secondary amines (e.g. diethylamine) [59].

The racemic and optically active isopropyl-phospholenes [8 and $(R)-\mathbf{8}]$ were also converted to the corresponding platinum complexes [cis-10 and $\operatorname{cis}-(S, S)-\mathbf{1 0}]$ by reaction with dichlorodibenzonitrile platinum. Using racemic isopropyl-phospholene (8) as the starting material, the given platinum complex was obtained as a 1:2 mixture of the homo- $[\operatorname{cis}-(R, R)-$ and $\operatorname{cis}-(S, S)-\mathbf{1 0}]$ and the heterochiral isomers $[\operatorname{cis}-(R, S)-\mathbf{1 0}]$. At the same time, application of the $(R)$-1-isopropyl-3-phospholene $[(R)-8]$ afforded the platinum complex exclusively in the corresponding homochiral form $[\operatorname{cis}-(S, S)-10]$ (Schemes 5 and 6).

The borane and platinum complexes [9 and 10] of $i$-propyl-3-phospholene were characterized by ${ }^{1} \mathrm{H},{ }^{13} \mathrm{C}$ and ${ }^{31} \mathrm{P}$ NMR spectroscopy, as well as with HRMS. Due to the highly congested spectra of platinum complexes $[\mathbf{1 0}$ and $(S, S)-\mathbf{1 0}], 2 \mathrm{D}{ }^{1} \mathrm{H}-{ }^{1} \mathrm{H}$ COSY, ${ }^{1} \mathrm{H}-{ }^{13} \mathrm{C}$ HSQC and HMBC experiments were also performed to verify the structure. According to expectations, the racemic and optically active platinum complexes [10 and $(S, S)-\mathbf{1 0}]$ contained 
the 3-phospholene [8 and $(R)-\mathbf{8}]$ ligands in cis position that was confirmed by the stereospecific ${ }^{1} J_{\mathrm{Pt}-\mathrm{P}}$ coupling constants of $3489 \mathrm{~Hz}$ measured for both $[\mathbf{1 0}]$ and $[(S, S)-\mathbf{1 0}]$. It is worth noting that the coupling constants of $c a .3500 \mathrm{~Hz}$ are of diagnostic value, and are characteristic for those coordinated phosphorus donor atoms possessing the chloro ligand in the trans position. The ${ }^{13} \mathrm{C}$ NMR spectra of the platinum complexes $[\mathbf{1 0}$ and $(S, S)-\mathbf{1 0}]$ were rather complicated because many signals were split due to ${ }^{195} \mathrm{Pt}-{ }^{13} \mathrm{C}$ and ${ }^{31} \mathrm{P}-{ }^{13} \mathrm{C}$ couplings, respectively. The corresponding coupling constants were determined by a first order analysis.

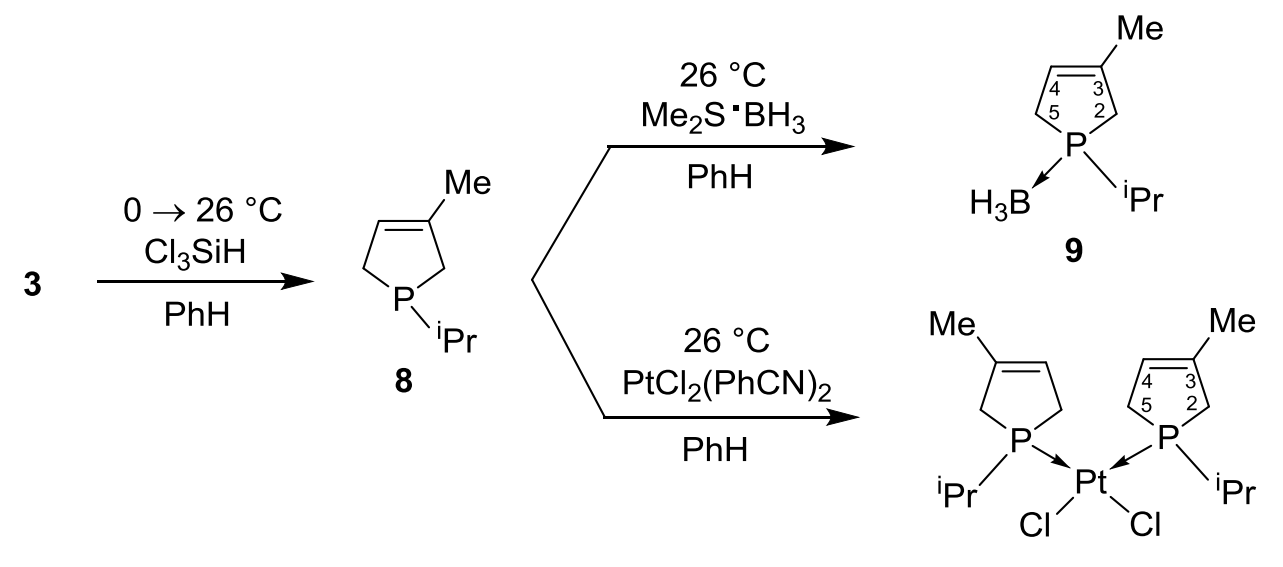

$(R, R)-10$ and $(S, S)-10$ (homochiral forms)

$(R, S)-10$ (heterochiral form)

\section{Scheme 5.}

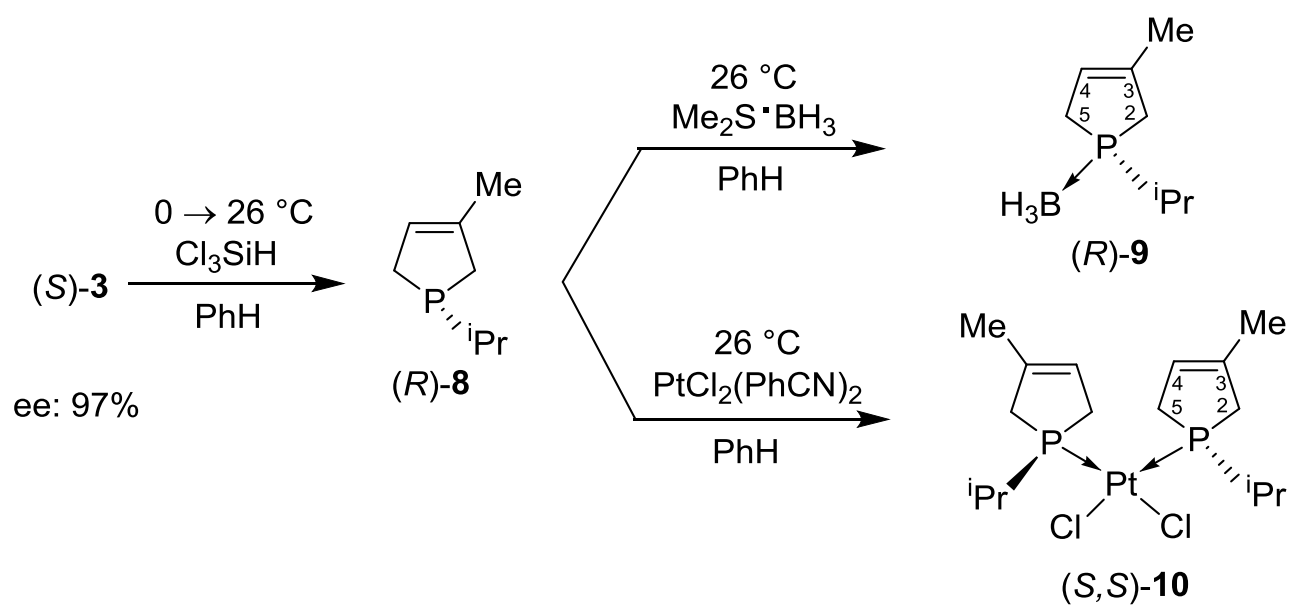

Scheme 6. 
Stereostructure of the isopropyl-phospholene - platinum complex (10) was calculated at the $\omega B 97 X-D / c c-p V T Z / / R I-B 97-D / 6-31 G(d)$ level of theory with cc-pVTZ-PP pseudopotential on the $\mathrm{Pt}$ atom. Accurate $\omega \mathrm{B} 97 \mathrm{X}-\mathrm{D}$ single point energy calculations suggested that the relative energies of the corresponding homochiral $[(R, R)$ and $(S, S)]$ and heterochiral $(R, S)$ isopropyl-phospholene - platinum complexes $(\mathbf{1 0})$ are close to each other within $0.6 \mathrm{kcal} / \mathrm{mol}$. The most stable structure of the synthesized cis-bis $((S)-1$-isopropyl-3methyl-3-phospholeno)-dichloro-platinum(II) $[(S, S)-10]$ is displayed in Fig. 6. We found that the conformer with rotational symmetry $\left(\mathrm{C}_{2}\right.$ symmetry group) is the most favourable structure which is stabilized by intramolecular nonbonding interactions between the phospholene ring and the corresponding alkyl group. The geometry around the Pt atom is considered square planar, as the $\mathrm{P}(1) \ldots \mathrm{Cl}(1) \ldots \mathrm{Cl}(2) \ldots \mathrm{P}(2)$ pseudo torsion angle is $-3.9^{\circ}$.

The structure of the complexes is determined by nonbonding interaction between the Pligands. $\mathrm{CH}$...HC interactions were identified between the $\mathrm{C}(2) \mathrm{H}_{2}$ moieties of the two phospholene rings (the shortest $\mathrm{H}$...H distance is $2.29 \AA$ ) and between the $\mathrm{C}(2) \mathrm{H}_{2}$ unit of the phospholene ring and the methyl group of the isopropyl substituent of the neighboring phospholene moiety (the shortest H...H distance is $2.22 \AA$, see Fig. 6). These secondary interactions also define the environment of the platinum influencing the properties of the catalyst. In case of $(S, S)$-10, one methyl group of each isopropyl substituent is situated, due to the $\mathrm{C}_{2}$ symmetry, close to the platinum atom, and it significantly influences the environment of the platinum that is shown by the $H \ldots \mathrm{Pt} \ldots \mathrm{Cl}(2) \ldots \mathrm{Cl}(1)$ dihedral angle of $96.1^{\circ}$ and the $\mathrm{H}_{2} \mathrm{CH}$...Pt distance of $3.04 \AA$ (where $H$ is the corresponding proton of one methyl group of the isopropyl substituent, See Fig. 6.) 


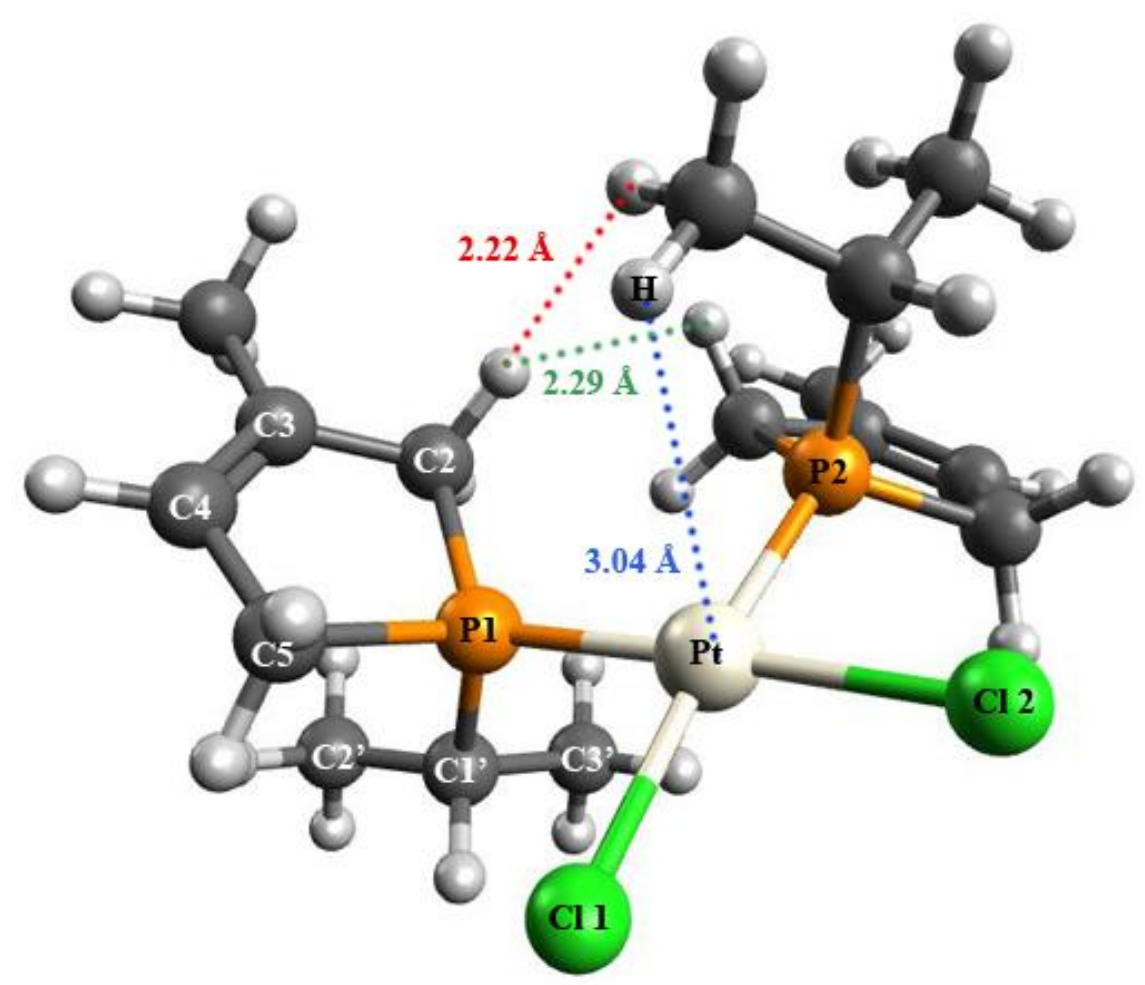

Fig. 6. Perspective view of $\operatorname{cis-bis((S)-1-isopropyl-3-methyl-3-phospholeno)-dichloro-}$ platinum(II) $[(S, S)-10]$ calculated by $\omega$ B97X-D/cc-pVTZ//RI-B97-D/6-31G(d) method. For Pt atoms, cc-pVTZ-PP pseudopotential was applied in all cases. Grey, white grey, orange, green and white colours are referred to carbon, hydrogen, phosphorus, chlorine and platinum atoms, respectively. Selected bond lengths $(\AA)$ and angles $\left(^{\circ}\right)$ are as follows: $\mathrm{Pt}-\mathrm{Cl}(1)$ 2.402, $\mathrm{Pt}-\mathrm{P}(1)$ 2.233, P(1)-C2 1.875, C2-C3 1.520, C3-C4 1.348, C4-C5 1.510, P(1)-C5 1.871, P(1)-C1' 1.866, C1'-C2' 1.540; Cl(1)-Pt-Cl(2) 90.7, Cl(1)-Pt-P(1) 84.6, Pt-P(1)-C2 121.7, Pt-P(1)-C5 115.6, Pt-P(1)-C1' 112.0, P(1)-C2-C3 105.3, C2-C3-C4 116.3, C3-C4-C5 118.7, C2-P(1)-C5 94.2, C2-P(1)-C1' 105.3, C5-P(1)-C1' 105.8, C2'-C1'-C3' 112.4; P(1)...Cl(1)...Cl(2)..P(2) -3.9, Cl(1)-Pt-P(1)-C2 161.1, Pt-P(1)-C1'-C3' -55.6, Pt-P(1)-C2-C3 -132.4, P(1)-C2-C3-C4 6.9, $\mathrm{P}(1)-\mathrm{C} 2-\mathrm{C} 3-\mathrm{CH}_{3}-174.4, \mathrm{C} 2-\mathrm{C} 3-\mathrm{C} 4-\mathrm{C} 5-0.5$. 
2.4. Catalytic activity of the 1-isopropyl-3-methyl-3-phospholene - platinum complex in the hydroformylation of styrene

The $\mathrm{PtCl}_{2} \mathrm{~L}_{2}$-type complexes [cis-10; cis-(S,S)-10] were tested as catalyst precursor in the hydroformylation of styrene. The catalysts formed in situ from cis-10 (or cis- $(S, S)-\mathbf{1 0}$ ) and two equivalents of tin(II) chloride were used under standard 'oxo-conditions' $\left[\mathrm{p}(\mathrm{CO})=\mathrm{p}\left(\mathrm{H}_{2}\right)=40 \mathrm{bar}, 100^{\circ} \mathrm{C}\right]$. As expected in the hydroformylation of styrene, in addition to the two types of formyl regioisomers, 2-arylpropanal (A) and 3-arylpropanal (B), ethylbenzene (C) as hydrogenation by-product was also formed (Eq. 1).

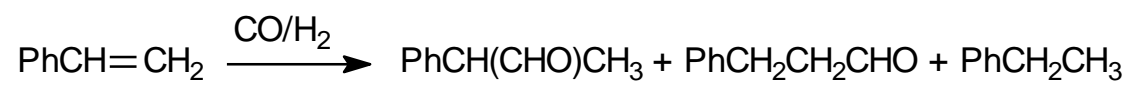

A $B$ C

The catalytic system is active at a temperature as low as $40{ }^{\circ} \mathrm{C}$. Considering the conversions obtained with similar catalysts but containing $P$-alkyl-phospholenes and phospholanes,[46] the catalytic activity was rather low.

The formation of the aldehydes ( $\mathbf{A}$ and $\mathbf{B}$ ) was preferred in all cases and chemoselectivities up to $93 \%$ were obtained. Slight increase in aldehyde selectivity was observed by increasing the reaction temperature (Table 4, Entries 1-3).

As regards the regioselectivity, the influence of the structure of the catalyst is even more pronounced. The branched aldehyde (A) predominated, when the ligand was used in racemic form, i.e., the catalyst precursor was a mixture of homo- and heterochiral forms $((R, R)-\mathbf{1 0}$, $(S, S)-10,(R, S)-10)$. A lower regioselectivity was observed, when the ligand was used in enantiomerically pure form, i.e., the catalyst precursor was a homochiral complex $((S, S)-\mathbf{1 0})$. For instance, $73 \%$ and $49 \%$ regioselectivities were obtained at $100{ }^{\circ} \mathrm{C}$, when racemic and enantiomerically pure ligands were used, respectively (Compare for instance entries 3 and 6). 
A similar change in regioselectivity was observed at $40{ }^{\circ} \mathrm{C}$ and $60{ }^{\circ} \mathrm{C}$ (entries 1,4 and 2, 5, respectively).

The explanation for the above phenomenon might be based on the different structure and reactivity of the diastereomeric transition states coordinating the substrate. The transition state complexes, coordinating the prochiral alkene (styrene) either to $(S, S)-\mathbf{1 0}$ or $(S, R)-\mathbf{1 0}$, reveal different reactivity towards alkene migratory insertion. Consequently, the ratio of the platinum(II)-branched alkyl intermediate to the corresponding linear alkyl intermediate might be different in case of homochiral and heterochiral complexes. If we suppose that the stereochemical outcome of the reaction is decided in this step (and not in the following COinsertion step), the unexpectedly large difference in regioselectivities can be rationalized.

Enantioselective hydroformylation only with low ee-s could be performed when the complex $(S, S)$-10 was used. The temperature-dependence of the ee-s is not pronounced.

Table 4. Hydroformylation of styrene in the presence of in situ formed catalysts from cis$\mathrm{PtCl}_{2}(\mathrm{~L})_{2}$ complex [cis-10; cis-(S,S)-10] and tin(II) chloride ${ }^{\mathrm{a}}$

\begin{tabular}{cccccccc}
\hline Entry & $\mathrm{L}$ & Temp. $\left({ }^{\circ} \mathrm{C}\right)$ & $\mathrm{R}$. time $(\mathrm{h})$ & Conv. $(\%)$ & $\mathrm{R}_{\mathrm{c}}{ }^{\mathrm{b}}(\%)$ & $\mathrm{R}_{\mathrm{br}}{ }^{\mathrm{c}}(\%)$ & e.e. $^{\mathrm{d}}(\%)$ \\
\hline 1 & $\mathbf{8}$ & 40 & 96 & 28 & 73 & 89 & - \\
2 & $\mathbf{8}$ & 60 & 72 & 30 & 87 & 77 & - \\
3 & $\mathbf{8}$ & 100 & 24 & 65 & 91 & 73 & - \\
4 & $(R)-\mathbf{8}$ & 40 & 96 & 24 & 84 & 69 & $7(S)$ \\
5 & $(R)-8$ & 60 & 72 & 27 & 90 & 52 & $10(S)$ \\
6 & $(R)-8$ & 100 & 24 & 85 & 93 & 49 & $10(S)$ \\
\hline
\end{tabular}

A: 2-phenylpropanal, B: 3-phenylpropanal, C: ethylbenzene.

${ }^{\mathrm{a}}$ Reaction conditions: Pt/styrene $=1 / 100, \mathrm{Pt} / \mathrm{SnCl}_{2}=1 / 2 ; \mathrm{p}(\mathrm{CO})=\mathrm{p}\left(\mathrm{H}_{2}\right)=40$ bar, $1 \mathrm{mmol}$ of styrene, solvent: $10 \mathrm{~mL}$ of toluene.

${ }^{\mathrm{b}}$ Chemoselectivity towards aldehydes $(\mathbf{A}, \mathbf{B})$. [(moles of $\mathbf{A}+$ moles of $\left.\mathbf{B}\right) /($ moles of $\mathbf{A}+$ moles of $\mathbf{B}+$ moles of C) $\times 100]$.

${ }^{c}$ Regioselectivity towards branched aldehyde (A). [moles of $\mathbf{A} /($ moles of $\mathbf{A}+$ moles of $\mathbf{B}) \times 100$ ].

\section{Conclusions}

The family of optically active 3-methyl-3-phospholene oxides was expanded by the enantiomers of 1-isopropyl derivative. The optical resolution of the racemate was performed 
in different ways applying either TADDOL derivatives, or the acidic $\mathrm{Ca}^{2+}$ salts of (-)-O,O'diaroyl-(2R,3R)-tartaric acids. In one case, the diastereomer associate could be analyzed by Xray chrystallography. The stochiometry of the associate and the stabilizing intermolecular contacts between the guest and the two host molecules were evaluated. The absolute configuration of the P-stereogenic center was also confirmed by CD spectroscopy and quantum chemical calculations. The racemic and optically active P-ligands obtained after deoxygenation were converted to the corresponding borane and platinum(II) complexes. Stereostructure of the latter $\mathrm{PtL}_{2} \mathrm{Cl}_{2}$ species (where L=isopropyl-3-methyl-3-phospholene) was evaluated by high level calculations and they were tested as catalyst in the hydroformylation of styrene. 


\section{Experimental}

\subsection{General (instruments)}

The ${ }^{31} \mathrm{P}$ NMR spectra were recorded on a Bruker AV-300 spectrometer operating at 121.5 $\mathrm{MHz}$, while the ${ }^{13} \mathrm{C}$ and ${ }^{1} \mathrm{H}$ NMR spectra were obtained on a Bruker DRX-500 spectrometer operating at 125.7 and $500 \mathrm{MHz}$, respectively. $2 \mathrm{D}{ }^{1} \mathrm{H}-{ }^{1} \mathrm{H}$ COSY,,${ }^{1} \mathrm{H}_{-}{ }^{13} \mathrm{C} \mathrm{HSQC}$ and $\mathrm{HMBC}$ spectra of platinum complexes [10 and $(S, S)-\mathbf{1 0}]$ were acquired on a Bruker Avance II spectrometer operating at $500 \mathrm{MHz}{ }^{1} \mathrm{H}$ frequency equipped with a BBI or a TXI z-gradient probe. The couplings are given in Hz. The exact mass measurements were performed using a Q-TOF Premier mass spectrometer in positive electrospray mode. The enantiomeric excess (ee) values of the phospholene oxide 3 were determined by chiral GC on Agilent 4890D instrument equipped with a GAMMA DEX ${ }^{\mathrm{TM}} 120$ column $(30 \mathrm{~m} \times 0.25 \mathrm{~mm}, 0.25 \mu \mathrm{m}$ film, FID detector, nitrogen as carrier gas, injector $240{ }^{\circ} \mathrm{C}$, detector $300^{\circ} \mathrm{C}$, head pressure: $10 \mathrm{psi}$, at 1:100 split ratio). Retention times of $\mathbf{3}$ by chiral GC (program: $40 \mathrm{~min}$ at $150{ }^{\circ} \mathrm{C}$ ): 30.2 min for $(R)-3$ and 30.9 min for $(S)$-3. The determination of the ee-s of 2-phenylpropanal (A) was carried out on Thermo Scientific FOCUS gas-chromatograph equipped with a Cyclodex column $(20 \mathrm{~m} \times 0.25 \mathrm{~mm}, 0.25 \mu \mathrm{m}$ film, FID detector, helium as carrier gas, injector $250{ }^{\circ} \mathrm{C}$, detector $280{ }^{\circ} \mathrm{C}$, head pressure: $14.5 \mathrm{psi}$ ). (S)-2-Phenylpropanal was eluted before the $(R)$-enantiomer. Optical rotations were determined on a Perkin-Elmer 241 polarimeter.

The (-)-(4R,5R)-4,5-bis(diphenylhydroxymethyl)-2,2-dimethyldioxolane [(-)-4], the (-)-(2R,3R)- $\alpha, \alpha, \alpha^{\prime}, \alpha^{\prime}$-tetraphenyl-1,4-dioxaspiro[4.5]decan-2,3-dimethanol [(-)-5] and the calcium hydrogen (-)-O, $O^{\prime}$-dibezoyl-(2R,3R)-tartrate [(-)-6] were synthesized as described earlier. (-)- $O, O^{\prime}$-Dibezoyl- and (-)- $O, O^{\prime}$ '-di- $p$-toluoyl-(2R,3R)-tartaric acid were purchased from Aldrich Chemical Co. 


\subsection{Preparation of 1-isopropyl-3-methyl-3-phospholene 1-oxide (3)}

To $14.1 \mathrm{~g}$ (106.4 mmol) of 1-hydroxy-3-phospholene 1-oxide (1) in $60 \mathrm{~mL}$ of chloroform was added $10.1 \mathrm{~mL}(138.4 \mathrm{mmol})$ of thionyl chloride and the solution was stirred overnight. The volatile components were removed in vacuo, and the residue was dissolved in $70 \mathrm{~mL}$ of THF. To the solution so obtained was added dropwise $159.7 \mathrm{mmol}$ of isopropylmagnesium bromide in $90 \mathrm{~mL}$ of THF (prepared from $4.1 \mathrm{~g}(167.7 \mathrm{mmol})$ of magnesium and $15 \mathrm{~mL}$ (159.7 mmol) of isopropyl bromide) at $0{ }^{\circ} \mathrm{C}$, and the mixture was stirred overnight. The mixture was then quenched with a $3 \mathrm{M} \mathrm{HCl}$ at $0{ }^{\circ} \mathrm{C}$. The two phases were separated, and the organic layer was washed with $\mathrm{NaHCO}_{3}$, brine and then dried $\left(\mathrm{Na}_{2} \mathrm{SO}_{4}\right)$. After evaporating the solvent, the residue so obtained was purified by column chromatography (silica gel, 3\% methanol in dichloromethane) to give $8.2 \mathrm{~g}$ (49\%) of 1-isopropyl-3-methyl-3-phospholene 1oxide (3) as a dense oil.

${ }^{1} \mathrm{H} \mathrm{NMR}\left(\mathrm{CDCl}_{3}\right) \delta 1.20(\mathrm{dd}, J=2.2,7.2,3 \mathrm{H})$ and $1.23(\mathrm{dd}, J=2.2,7.1,3 \mathrm{H}) \mathrm{CH}\left(\mathrm{CH}_{3}\right)_{2}$, 1.79 (bs, 3H, $\left.\mathrm{C}_{3}-\mathrm{CH}_{3}\right), 1.95-2.05\left(\mathrm{~m}, 1 \mathrm{H}, \mathrm{CH}\left(\mathrm{CH}_{3}\right)_{2}\right), 2.38-2.52\left(\mathrm{~m}, 4 \mathrm{H}, \mathrm{CH}_{2} \mathrm{PCH}_{2}\right), 5.49$ (m, $1 \mathrm{H}, \mathrm{CH}=) ;{ }^{13} \mathrm{C} \mathrm{NMR}\left(\mathrm{CDCl}_{3}\right) \delta 15.5$ and $15.6\left(\mathrm{CH}\left(\mathrm{CH}_{3}\right)_{2}\right), 20.3\left({ }^{3} \mathrm{~J}_{\mathrm{P}-\mathrm{C}}=10, \mathrm{C}_{3}-\mathrm{CH}_{3}\right), 28.4$ $\left({ }^{1} J_{\mathrm{P}-\mathrm{C}}=64, \mathrm{C}_{1}{ }^{9}\right), 30.4\left({ }^{1} J_{\mathrm{P}-\mathrm{C}}=61, \mathrm{C}_{5}\right), 33.5\left({ }^{1} J_{\mathrm{P}-\mathrm{C}}=64, \mathrm{C}_{2}\right), 121.2\left({ }^{2} J_{\mathrm{P}-\mathrm{C}}=7, \mathrm{C}_{4}\right), 137.1\left({ }^{2} J_{\mathrm{P}-\mathrm{C}}\right.$ $\left.=12, \mathrm{C}_{3}\right) ;{ }^{31} \mathrm{P} \mathrm{NMR}\left(\mathrm{CDCl}_{3}\right) \delta 76.0 ; \mathrm{HRMS}[\mathrm{M}+\mathrm{H}]^{+}$found $=159.0934, \mathrm{C}_{8} \mathrm{H}_{16} \mathrm{OP}$ requires 158.0861.

4.3. Resolution of 1-isopropyl-3-methyl-3-phospholene 1-oxide (3) with TADDOL [(-)-4] (Representative Procedure I.)

$0.15 \mathrm{~g}$ (0.95 mmol) of racemic 1-isopropyl-3-methyl-3-phospholene 1-oxide (3) and 0.22 $\mathrm{g}(0.48 \mathrm{mmol})$ of TADDOL [(-)-4] was dissolved in $0.44 \mathrm{~mL}$ of hot ethyl acetate, and then $2.2 \mathrm{~mL}$ of hexane was added. Colourless crystalline diastereomeric complex $(R)$ 3.(TADDOL) appeared immediately. After standing at $26{ }^{\circ} \mathrm{C}$ for $3 \mathrm{~h}$, the crystals were 
separated by filtration to give $0.29 \mathrm{~g}(98 \%)$ of $(R)-3 \cdot($ TADDOL) with a de of $2 \%$. The diastereomeric complex $(R)-3 \cdot($ TADDOL) was purified further by two recrystallizations from a mixture of $0.44 \mathrm{~mL}$ of ethyl acetate and $2.2 \mathrm{~mL}$ of hexane to afford $0.25 \mathrm{~g}(84 \%)$ of the complex $(R)-3 \cdot($ TADDOL) with a de of $6 \%$. The $(R)$-1-isopropyl-3-methyl-3-phospholene 1oxide $[(R)-3]$ was recovered from the diastereomer by column chromatography (silica gel, dichloromethane-methanol 97:3) to give $0.061 \mathrm{~g}(81 \%)$ of phospholene oxide $(R)-\mathbf{3}$ with an ee of $6 \%$ (Table 1, Entry 1). Resolution of 1-isopropyl-3-methyl-3-phospholene 1-oxide (3) with TADDOL [(-)-4] was also performed using isopropyl alcohol. In this instance, the racemic isopropyl-phospholene oxide $\mathbf{3}$ and the TADDOL [(-)-4] were dissolved in hot isopropyl alcohol, and the corresponding diastereomeric complex $[(R)-3 \cdot($ TADDOL $)]$ precipitated by cooling the mixture to $26{ }^{\circ} \mathrm{C}$ (Table 1, Entry 2).

4.4. Resolution of 1-isopropyl-3-methyl-3-phospholene 1-oxide (3) with spiro-TADDOL $[(-)-5]$

The resolution of 1-isopropyl-3-methyl-3-phospholene 1-oxide (3) with spiro-TADDOL [(-)-5] was carried out according to Representative Procedure I. The conditions and the results are shown in Table 1, Entries 3-6.

4.5. Preparation of both enantiomers of 1-isopropyl-3-methyl-3-phospholene 1-oxide [(S)- and (R)-3] with spiro-TADDOL [(-)-5]

The (S)-1-isopropyl-3-methyl-3-phospholene 1-oxide $[(S)-3]$ was obtained by the resolution of $0.71 \mathrm{~g}(4.5 \mathrm{mmol})$ of racemic 3 with $2.3 \mathrm{~g}(4.5 \mathrm{mmol})$ of spiro-TADDOL [(-)-5] in $13.6 \mathrm{~mL}$ of ethanol according to Representative Procedure I. The diastereomeric complex $\left[(S)-3 \cdot(\text { spiro-TADDOL })_{2}\right]$ was purified by three recrystallizations in $13.6 \mathrm{~mL}$ of ethanol. The (S)-1-isopropyl-3-methyl-3-phospholene 1-oxide [(S)-3] was recovered by column 
chromatography (silica gel, dichloromethane-methanol 97:3) to give $0.16 \mathrm{~g}(45 \%)$ of $(S)$-3 in an ee of $97 \%\left[[\alpha]_{D}^{25}=-12.8\left(\mathrm{c} 0.8, \mathrm{CHCl}_{3}\right)\right]$. The mother liquors of the crystallization and recrystallizations were combined, and the solvent was evaporated to afford $1.71 \mathrm{~g} \mathrm{(150 \% )}$ of a white powder as a 1:0.69 mixture of $(R)-3$ with an ee of $23 \%$ and spiro-TADDOL [(-)-5]. $0.91 \mathrm{~g}(1.8 \mathrm{mmol})$ of spiro-TADDOL $[(-)-5]$ was added to this mixture and the resolution was performed in $11.5 \mathrm{~mL}$ of methanol according to Representative Procedure $I$. The $[(R)$ 3·(spiro-TADDOL $)_{2}$ ] complex was purified by two recrystallizations in $11.5 \mathrm{~mL}$ of methanol and it was decomposed by column chromatography (silica gel, dichloromethane-methanol 97:3) to give $0.14 \mathrm{~g}(40 \%)$ of $(R)$-1-isopropyl-3-methyl-3-phospholene 1-oxide $[(R)-3]$ in an ee of $87 \%$.

4.6. Resolution of 1-isopropyl-3-methyl-3-phospholene 1-oxide (3) with calcium hydrogen O,O'-dibenzoyl-(2R,3R)-tartrate [(-)-6] (Representative Procedure II.)

To $0.14 \mathrm{~g}(0.17 \mathrm{mmol})$ of $\mathrm{Ca}(\mathrm{H}-\mathrm{DBTA})_{2} \cdot\left(\mathrm{H}_{2} \mathrm{O}\right)_{2}\left[(-)-6 \cdot\left(\mathrm{H}_{2} \mathrm{O}\right)_{2}\right]$ in $0.40 \mathrm{~mL}$ of hot ethanol was added $0.11 \mathrm{~g}(0.69 \mathrm{mmol})$ of racemic 1-isopropyl-3-methyl-3-phospholene 1-oxide $(\mathbf{3})$ in $0.40 \mathrm{~mL}$ of ethanol. After the addition, the solution was allowed to cool to $26^{\circ} \mathrm{C}$, whereupon colourless crystals appeared. After standing at $26{ }^{\circ} \mathrm{C}$ for $24 \mathrm{~h}$, the crystals were filtered off to give $0.60 \mathrm{~g}(33 \%)$ of $\mathrm{Ca}\left[((R)-3)_{2}(\mathrm{H}-\mathrm{DBTA})_{2}\right]$ with a de of $35 \%$. The diastereomeric complex was purified further by one digestion, by stirring the suspension of the diastereomeric complex at $26{ }^{\circ} \mathrm{C}$ in $0.80 \mathrm{~mL}$ of ethanol for $24 \mathrm{~h}$ to give $0.022 \mathrm{~g}(12 \%)$ of $\mathrm{Ca}\left[((R)-3)_{2}(\mathrm{H}-\mathrm{DBTA})_{2}\right]$ with a de of $43 \%$. The $(R)$-1-isopropyl-3-methyl-3-phospholene 1oxide $[(R)-3]$ was recovered from the diastereomeric complex by treatment of the $2 \mathrm{~mL}$ dichloromethane suspension of $\mathrm{Ca}\left[((R)-3)_{2}(\mathrm{H}-\mathrm{DBTA})_{2}\right]$ with $2 \mathrm{~mL}$ of a $10 \%$ aqueous ammonia. The organic layer was washed with $0.5 \mathrm{~mL}$ of water, dried $\left(\mathrm{Na}_{2} \mathrm{SO}_{4}\right)$, and 
concentrated to give $0.004 \mathrm{~g}(8 \%)$ of $(R)$-1-isopropyl-3-methyl-3-phospholene 1-oxide [(R)-3] with an ee of $43 \%$ (Table 3, Entry 1).

Resolution of isopropyl-3-methyl-3-phospholene 1-oxide (3) with $\mathrm{Ca}(\mathrm{H}-\mathrm{DBTA})_{2}[(-)-6]$ was also performed in a mixture of ethanol and ethyl acetate and that of ethanol and acetonitrile according to Representative Procedure II. The conditions and the results are shown in Table 3, Entries 2 and 3.

4.7. Resolution of 1-isopropyl-3-methyl-3-phospholene 1-oxide (3) with calcium hydrogen O,O'-di-p-toluoyl-(2R,3R)-tartrate [(-)-7] (Representative Procedure III.)

To $0.19 \mathrm{~g}(0.48 \mathrm{mmol})$ of DPTTA $\cdot \mathrm{H}_{2} \mathrm{O}$ in a mixture of $0.60 \mathrm{~mL}$ of ethanol and $0.06 \mathrm{~mL}$ of water was added $0.014 \mathrm{~g}(0.24 \mathrm{mmol})$ of $\mathrm{CaO}$, and the mixture was heated at the boiling point until it became clear. $0.15 \mathrm{~g}(0.97 \mathrm{mmol})$ of racemic 1-isopropyl-3-methyl-3-phospholene 1oxide (3) in $0.60 \mathrm{~mL}$ of ethyl acetate was then added to the solution of the in situ formed resolving agent $\mathrm{Ca}(\mathrm{H}-\mathrm{DPTTA})_{2}[(-)-7]$. After the addition, the solution was allowed to cool down to $26{ }^{\circ} \mathrm{C}$, whereupon colourless crystals appeared. After standing at $26{ }^{\circ} \mathrm{C}$ for $24 \mathrm{~h}$, the crystals were filtered off to give $0.12 \mathrm{~g}(45 \%)$ of $\mathrm{Ca}\left[((S)-3)_{2}(\mathrm{H} \text {-DPTTA })_{2}\right]$ with a de of $46 \%$. The diastereomeric complex was purified further by two digestions, by stirring the suspension of the diastereomeric complex at $26^{\circ} \mathrm{C}$ for $24 \mathrm{~h}$ in a mixture of $0.60 \mathrm{~mL}$ of ethanol and 0.60 $\mathrm{mL}$ of ethyl acetate to give $0.038 \mathrm{~g}(14 \%) \mathrm{Ca}\left[((S)-3)_{2}(\mathrm{H}-\mathrm{DPTTA})_{2}\right]$ with a de of $92 \%$.

The $(S)$-1-isopropyl-3-methyl-3-phospholene 1-oxide $[(S)$-3] was recovered from the corresponding diastereomeric complex similarly to the procedure described in Section 4.6 to afford $0.008 \mathrm{~g}(10 \%)$ of $(S)$-1-isopropyl-3-methyl-3-phospholene 1-oxide [(S)-3] with an ee of 92\% (Table 3, Entry 5).

Resolution of isopropyl-3-methyl-3-phospholene 1-oxide (3) with Ca(H-DPTTA) 2 [(-)-7] was also performed in a mixture of ethanol and water and that of ethanol, water and 
acetonitrile according to Representative Procedure III. The conditions and the results are shown in Table 3, Entries 4 and 6.

\subsection{Preparation of 1-isopropyl-3-methyl-3-phospholene-borane (9)}

The solution of $0.11 \mathrm{~g}(0.68 \mathrm{mmol})$ of racemic 1-isopropyl-3-methyl-3-phospholene 1oxide (3) in $2 \mathrm{~mL}$ of toluene was degassed and cooled to $0{ }^{\circ} \mathrm{C}$, then $0.56 \mathrm{~mL}(4.1 \mathrm{mmol})$ of trichlorosilane was added. The mixture was stirred at $0{ }^{\circ} \mathrm{C}$ for $3 \mathrm{~h}$ and then at $26{ }^{\circ} \mathrm{C}$ for $3 \mathrm{~h}$ under nitrogen to afford the corresponding phospholene (8) that was immediately reacted further. $0.34 \mathrm{~mL}$ of $2 \mathrm{M}$ dimethyl sulfide borane in tetrahydrofuran $(0.68 \mathrm{mmol})$ was added and the solution was stirred at $26^{\circ} \mathrm{C}$ for $3 \mathrm{~h}$ under nitrogen. Then, the mixture was treated with $3 \mathrm{~mL}$ of water and stirred for $15 \mathrm{~min}$. The precipitated boric acid was removed by filtration and the organic phase dried $\left(\mathrm{Na}_{2} \mathrm{SO}_{4}\right)$. Volatile components were removed under reduced pressure and the residue so obtained was purified by column chromatography (silica gel, $3 \%$ methanol in dichloromethane) to give $0.041 \mathrm{~g}$ (38\%) of 1-isopropyl-3-methyl-3phospholene-borane (9). ${ }^{1} \mathrm{H}$ NMR $\left(\mathrm{CDCl}_{3}\right) \delta$ 0.35-1.04 (m, 3H, $\left.\mathrm{BH}_{3}\right), \delta 1.12(\mathrm{~d}, J=7.1,3 \mathrm{H})$ and $1.18(\mathrm{~d}, J=7.1,3 \mathrm{H}) \mathrm{CH}\left(\mathrm{CH}_{3}\right)_{2}, 1.80\left(\mathrm{bs}, 3 \mathrm{H}, \mathrm{C}_{3}-\mathrm{CH}_{3}\right), 1.84-1.97\left(\mathrm{~m}, 1 \mathrm{H}, \mathrm{CH}\left(\mathrm{CH}_{3}\right)_{2}\right)$, 2.34-2.56 (m, 4H, $\left.\mathrm{CH}_{2} \mathrm{PCH}_{2}\right), 5.43(\mathrm{~m}, 1 \mathrm{H}, \mathrm{CH}=) ;{ }^{13} \mathrm{C} \mathrm{NMR}\left(\mathrm{CDCl}_{3}\right) \delta 16.6$ and 16.7 $\mathrm{CH}\left(\mathrm{CH}_{3}\right)_{2}, 19.1\left({ }^{3} J_{\mathrm{P}-\mathrm{C}}=7, \mathrm{C}_{3}-\mathrm{CH}_{3}\right), 24.1\left({ }^{1} J_{\mathrm{P}-\mathrm{C}}=31, \mathrm{C}_{1}\right), 28.4\left({ }^{1} J_{\mathrm{P}-\mathrm{C}}=33, \mathrm{C}_{5}\right), 32.2\left({ }^{1} J_{\mathrm{P}-\mathrm{C}}=\right.$ 35, $\left.\mathrm{C}_{2}\right), 122.2\left(\mathrm{C}_{4}\right), 138.2\left({ }^{2} J_{\mathrm{P}-\mathrm{C}}=3, \mathrm{C}_{3}\right) ;{ }^{31} \mathrm{P} \mathrm{NMR}\left(\mathrm{CDCl}_{3}\right) \delta 42.9$ (broad); $[\mathrm{M}+\mathrm{Na}]^{+}$found $=$ 179.1134, $\mathrm{C}_{8} \mathrm{H}_{18} \mathrm{PBNa}$ requires 179.1131 for the ${ }^{11} \mathrm{~B}$ isotope.

The optically active $(R)$-1-isopropyl-3-methyl-3-phospholene-borane $[(R)-9]$ was prepared in a similar manner from $(S)$-1-isopropyl-3-methyl-3-phospholene 1-oxide $[(S)$-3] with an ee of 97\%. Yield of (R)-9: 40\%; ${ }^{1} \mathrm{H}$ NMR $\left(\mathrm{CDCl}_{3}\right) \delta 0.40-1.05\left(\mathrm{~m}, 3 \mathrm{H}, \mathrm{BH}_{3}\right), \delta 1.12(\mathrm{~d}, J=7.0$, $3 \mathrm{H})$ and $1.18(\mathrm{~d}, J=7.0,3 \mathrm{H}) \mathrm{CH}\left(\mathrm{CH}_{3}\right)_{2}, 1.80\left(\mathrm{bs}, 3 \mathrm{H}, \mathrm{C}_{3}-\mathrm{CH}_{3}\right), 1.86-1.97(\mathrm{~m}, 1 \mathrm{H}$, 
$\left.\mathrm{CH}\left(\mathrm{CH}_{3}\right)_{2}\right), 2.32-2.55\left(\mathrm{~m}, 4 \mathrm{H}, \mathrm{CH}_{2} \mathrm{PCH}_{2}\right), 5.43(\mathrm{~m}, 1 \mathrm{H}, \mathrm{CH}=) ;{ }^{13} \mathrm{C} \mathrm{NMR}\left(\mathrm{CDCl}_{3}\right) \delta 16.6$ and 16.7 $\mathrm{CH}\left(\mathrm{CH}_{3}\right)_{2}, 19.2\left({ }^{3} J_{\mathrm{P}-\mathrm{C}}=7, \mathrm{C}_{3}-\mathrm{CH}_{3}\right), 24.0\left({ }^{1} J_{\mathrm{P}-\mathrm{C}}=31, \mathrm{C}_{1}\right), 28.4\left({ }^{1} J_{\mathrm{P}-\mathrm{C}}=33, \mathrm{C}_{5}\right), 32.1\left({ }^{1} J_{\mathrm{P}-}\right.$ $\left.\mathrm{C}=35, \mathrm{C}_{2}\right), 122.2\left(\mathrm{C}_{4}\right), 138.2\left({ }^{2} J_{\mathrm{P}-\mathrm{C}}=3, \mathrm{C}_{3}\right) ;{ }^{31} \mathrm{P} \mathrm{NMR}\left(\mathrm{CDCl}_{3}\right) \delta 43.2(\mathrm{broad}) ;\left[[\alpha]_{D}^{25}=+3.8\right.$ (c $\left.\left.1, \mathrm{CHCl}_{3}\right)\right]$.

\subsection{Preparation of cis-[bis(1-isopropyl-3-methyl-3-phospholeno)-dichloro-platinum(II)] (10)}

The deoxygenation of $0.067 \mathrm{~g}(0.43 \mathrm{mmol})$ of racemic 1-isopropyl-3-methyl-3phospholene 1-oxide (3) was carried out in benzene using $0.26 \mathrm{~mL}$ (2.6 mmol) of trichlorosilane according to the procedure described in Section 4.8. Then, $0.10 \mathrm{~g}(0.21 \mathrm{mmol})$ of dichlorodibenzonitrile-platinum(II) was added to the reaction mixture under nitrogen. The mixture was stirred at $26^{\circ} \mathrm{C}$ for 1 day, whereupon the complex precipitated. Separation by filtration led to $0.10 \mathrm{~g}(87 \%)$ of $\mathbf{1 0}$ as a $2: 1$ mixture of the hetero- $(R, S)$ and homochiral $[(R, R)$ and $(S, S)]$ forms. ${ }^{1} \mathrm{H}$ NMR $\left(\mathrm{CDCl}_{3}\right) \delta 1.13-1.24\left(\mathrm{~m}, 12 \mathrm{H}, \mathrm{CH}\left(\mathrm{CH}_{3}\right)_{2}\right), 1.81\left(\mathrm{bs}, 6 \mathrm{H}, \mathrm{C}_{3}-\mathrm{CH}_{3}\right)$, 2.51-2.63 (m, 2H, $\left.\mathrm{CH}\left(\mathrm{CH}_{3}\right)_{2}\right), 2.74-3.12\left(\mathrm{~m}, 8 \mathrm{H}, \mathrm{CH}_{2} \mathrm{PCH}_{2}\right), 5.47(\mathrm{~m}, 2 \mathrm{H}, \mathrm{CH}=) ;{ }^{13} \mathrm{C} \mathrm{NMR}$ $\left(\mathrm{CDCl}_{3}\right) \delta$ 17.8-17.9 (m) and 18.1-18.3 (m) $\mathrm{CH}\left(\mathrm{CH}_{3}\right)_{2}$ of the homochiral form, 17.9-18.1 (m, $\mathrm{CH}\left(\mathrm{CH}_{3}\right)_{2}$ of the heterochiral form), 18.8-18.9 (m, $\left.\mathrm{C}_{3}-\mathrm{CH}_{3}\right), 27.7-28.1\left(\mathrm{~m}, \mathrm{C}_{1}{ }^{\prime}\right), 30.5-31.2(\mathrm{~m}$, $\left.\mathrm{C}_{5}\right), 34.4-35.0\left(\mathrm{~m}, \mathrm{C}_{2}\right), 122.7\left({ }^{3} \mathrm{Jt}_{\mathrm{Pt}-\mathrm{C}}=\right.$ cannot be observed, $\mathrm{C}_{4}$ of the homochiral form $), 122.9$ $\left({ }^{3} J_{\mathrm{Pt}-\mathrm{C}}=29, \mathrm{C}_{4}\right.$ of the heterochiral form $), 138.9-139.0\left(\mathrm{~m}, \mathrm{C}_{3}\right.$ of the heterochiral form $), 139.2-$ 139.3 (m, $\mathrm{C}_{3}$ of the homochiral form); ${ }^{31} \mathrm{P} \mathrm{NMR}\left(\mathrm{CDCl}_{3}\right) \delta 29.7\left({ }^{1} J_{\mathrm{Pt}-\mathrm{P}}=3489\right)$; HRMS [M$\mathrm{Cl}]^{+}$found $=513.1146, \mathrm{C}_{16} \mathrm{H}_{30} \mathrm{P}_{2} \mathrm{ClPt}$ requires 513.1138 for the ${ }^{35} \mathrm{Cl}$ and ${ }^{195} \mathrm{Pt}$ isotopes.

The optically active cis-[bis-(S)- 1-isopropyl-3-methyl-3-phospholeno)-dichloroplatinum(II)] $[(S, S)-10]$ was prepared in a similar manner from $(S)$-1-isopropyl-3-methyl-3phospholene 1-oxide $[(S)-3]$ with an ee of 97\%. Yield of $(R)-9: 75 \%$. $[\alpha]_{D}^{25}=+18.8(\mathrm{c} 1$, $\left.\mathrm{CHCl}_{3}\right) ;{ }^{1} \mathrm{H}$ NMR $\left(\mathrm{CDCl}_{3}\right) \delta 1.15\left(\mathrm{dd},{ }^{3} J_{\mathrm{H}-\mathrm{H}}=7.1,{ }^{3} J_{\mathrm{P}-\mathrm{H}}=16.7,6 \mathrm{H}, \mathrm{CH}\left(\mathrm{CH}_{3}\right)_{2}\right), 1.18\left(\mathrm{dd},{ }^{3} J_{\mathrm{H}-}\right.$ 
$\left.{ }_{\mathrm{H}}=7.2,{ }^{3} \mathrm{~J}_{\mathrm{P}-\mathrm{H}}=17.2,6 \mathrm{H}, \mathrm{CH}\left(\mathrm{CH}_{3}\right)_{2}\right), 1.79\left(\mathrm{bs}, 6 \mathrm{H}, \mathrm{C}_{3}-\mathrm{CH}_{3}\right), 2.48-2.58\left(\mathrm{~m}, 2 \mathrm{H}, \mathrm{CH}\left(\mathrm{CH}_{3}\right)_{2}\right)$, 2.77-2.89 (m, 6H, $\left.\mathrm{CH}_{2} \mathrm{PCH}_{2}\right), 2.95-3.10\left(\mathrm{~m}, 2 \mathrm{H}, \mathrm{CH}_{2} \mathrm{PCH}_{2}\right), 5.44(\mathrm{~m}, 2 \mathrm{H}, \mathrm{CH}=) ;{ }^{13} \mathrm{C} \mathrm{NMR}$ $\left(\mathrm{CDCl}_{3}\right) \delta 17.8\left({ }^{3} J_{\mathrm{Pt}-\mathrm{C}}=22\right)$ and $18.2\left({ }^{3} J_{\mathrm{Pt}-\mathrm{C}}=20\right) \mathrm{CH}\left(\mathrm{CH}_{3}\right)_{2}, 18.8\left({ }^{4} J_{\mathrm{Pt}-\mathrm{C}}=33,{ }^{3} J_{\mathrm{P}-\mathrm{C}}=4,{ }^{5} J_{\mathrm{P}-\mathrm{C}}\right.$ $\left.=4, \mathrm{C}_{3}-\mathrm{CH}_{3}\right), 27.9\left({ }^{2} J_{\mathrm{Pt}-\mathrm{C}}=31,{ }^{1} J_{\mathrm{P}-\mathrm{C}}=40,{ }^{3} J_{\mathrm{P}-\mathrm{C}}=6, \mathrm{C}_{1}\right), 30.7\left({ }^{2} J_{\mathrm{Pt}-\mathrm{C}}=54,{ }^{1} J_{\mathrm{P}-\mathrm{C}}=42,{ }^{3} J_{\mathrm{P}-\mathrm{C}}=\right.$ $\left.4, \mathrm{C}_{5}\right), 34.8\left({ }^{2} J_{\mathrm{Pt}-\mathrm{C}}=46,{ }^{1} J_{\mathrm{P}-\mathrm{C}}=46,{ }^{3} J_{\mathrm{P}-\mathrm{C}}=4, \mathrm{C}_{2}\right), 122.7\left({ }^{3} J_{\mathrm{Pt}-\mathrm{C}}=26, \mathrm{C}_{4}\right), 139.2\left({ }^{3} J_{\mathrm{Pt}-\mathrm{C}}=28\right.$, $\left.\mathrm{C}_{3}\right) ;{ }^{31} \mathrm{P} \mathrm{NMR}\left(\mathrm{CDCl}_{3}\right) \delta 29.7\left({ }^{1} J_{\mathrm{Pt}-\mathrm{P}}=3489\right) ;$ HRMS $[\mathrm{M}-\mathrm{Cl}]^{+}$found $=513.1129, \mathrm{C}_{16} \mathrm{H}_{30} \mathrm{P}_{2} \mathrm{ClPt}$ requires 513.1138 for the ${ }^{35} \mathrm{Cl}$ and ${ }^{195} \mathrm{Pt}$ isotopes.

\subsection{Hydroformylation experiments}

In a typical experiment, a solution of $\mathrm{PtCl}_{2}(\text { ligand })_{2}(\mathbf{1 0}$ or $(S, S)-\mathbf{1 0}, 5.5 \mathrm{mg}, 0.01 \mathrm{mmol})$ and tin(II) chloride $(3.8 \mathrm{mg} ; 0.02 \mathrm{mmol})$ in toluene $(10 \mathrm{~mL})$ containing styrene $(0.115 \mathrm{~mL}, 1.0$ mmol) was transferred under argon into a $100 \mathrm{~mL}$ stainless steel autoclave. The reaction vessel was pressurized to 80 bar total pressure $\left(\mathrm{CO} / \mathrm{H}_{2}=1: 1\right)$ and placed in an oil bath of constant temperature. The mixture was stirred with a magnetic stirrer for the given reaction time. The pressure was monitored throughout the reaction. After cooling and venting of the autoclave, the pale yellow solution was removed and immediately analyzed by GC, chiral GC (on a capillary Cyclodex column, $(R)$-2-phenylpropanal was eluted before the $(S)$ enantiomer) and GC-MS.

\subsection{X-Ray measurements}

A crystal of the diastereomeric complex incorporating (-)-3 and (-)-5 in a ratio of $1: 2$ was mounted on a glass fibre. Cell parameters were determined by least-squares from the respective setting angles as quoted. Completeness were equal or greater to $2 \theta=99.5 \%$. Multiscan absorption correction was applied to the data with minimum and maximum transmission factors of 0.965 and 0.992 . Initial structure models were obtained by direct methods [60] and 
subsequent difference syntheses. Anisotropic full-matrix least-squares refinement on F2 were applied [60] for all non-hydrogen atoms and the model was refined to convergence. Hydrogen atomic positions were calculated from assumed geometries where appropriate. Four $\mathrm{O}-\mathrm{H}$ hydrogen atoms were located from difference electron density maps. Hydrogen atoms were included in structure factor calculations and the non-trivial hydrogen positions and their isotropic displacements were refined. Other $\mathrm{H}$ atoms were kept riding on their anchor atoms, with isotropic displacement parameters of these hydrogen atoms were approximated from the $\mathrm{U}(\mathrm{eq})$ value of the atom they were bonded. The maximum and minimum residual electron densities in the final difference maps are 0.19 and -0.23 e. $\AA^{-3}$ and are normal. All further calculations and drawings were done by using PLATON [61], Mercury [51] and SCHAKAL [62]. Crystal structure data are deposited with the Cambridge Crystallographic Data Centre under CCDC 1405185 and can be obtained free of charge upon application.

\subsection{CD spectroscopy}

The UV and CD spectra were measured in acetonitrile solutions at $25^{\circ} \mathrm{C}$. The UV spectra were recorded on an Agilent 8453 diode array spectrometer. The CD spectra were taken on a Jasco J-810 spectropolarimeter.

The Marvin [63], Gaussian 09 [64], and MRCC [65] packages were used for the MM, DFT, and dRPA calculations. In the MM conformational analysis, the MMFF [66] force field was applied. The geometry optimizations were carried out at the DFT level using the PBE0 $[67,68]$ functional and the aug-cc-pVTZ [69] basis set. For the calculations of the absorption and CD spectra, a time-dependent DFT (TD-DFT) [70] method was used with the same functional and basis set. Rotator strengths were calculated in the velocity gauge. To mimic the experimental conditions all the DFT calculations were performed using the polarized continuum model (PCM) [71] with acetonitrile as the solvent. The dRPA energies were 
computed with the aug-cc-pVTZ basis set and PBE0 orbitals. To calculate the $298 \mathrm{~K}$ Gibbs energies of the conformers in the solvent, the gas-phase dRPA energies were adjusted by temperature corrections, entropy contributions, and Gibbs energies of solvation evaluated at the DFT level.

\subsection{Theoretical calculations}

Geometries were computed at the RI-B97-D/6-31G(d) level of theory [72-75] then single point energy calculations were performed at the optima using $\omega$ B97X-D/cc-pVTZ level [76,77]. For Pt atoms, cc-pVTZ-PP pseudopotential [78] was applied for both geometry optimization and single point energy calculations. Minima on the potential energy surface (PES) were characterized by harmonic vibrational frequency calculations. Calculations were carried out using Gaussian09 [64] program. Avogadro was utilized for visualization [79].

\section{Acknowledgements}

The authors are thankful to Hungarian Research Fund for financial support (Grant No. K83118, K108752, K104769 and K113177). This work was financially supported by the New Széchenyi Development Plan (TÁMOP-4.2.1/B-09/1/KMR-2010-0002). TS is grateful for the support of The New Széchenyi Plan TAMOP-4.2.2/B-10/1-2010-0009. Financial support from OTKA K 105459 (to K.E.K.) and from Richter Gedeon Talentum Alapítvány (Ph.D. scholarship to I.T.) is gratefully acknowledged. 


\section{References}

[1] H. Brunner, W. Zettlmeier, Handbook of Enantioselective Catalysis with Transition Metal Compounds, VCH, Weinheim, 1993.

[2] C. Botteghi, M. Marchetti, S. Paganelli, in: M. Beller, C. Bolm (Eds.), Transition Metals for Organic Synthesis, Wiley-VCH, Weinheim, 1998.

[3] R. Noyori, Asymmetric Catalysis in Organic Synthesis, John Wiley \& Sons, New York, 1994.

[4] F. Mathey, The Rise of a New Domain, in: Phosphorus-Carbon Heterocyclic Chemistry, Pergamon/Elsevier, Amsterdam, 2001.

[5] L. Kollár, G. Keglevich, Chem. Rev. 110 (2010) 4257.

[6] A. Grabulosa, P-Stereogenic Ligands in Enantioselective Catalysis, The Royal Society of Chemistry, Cambridge, 2010.

[7] O.I. Kolodiazhnyi, Tetrahedron: Asymmetry 9 (1998) 1279.

[8] O.I. Kolodiazhnyi, Tetrahedron: Asymmetry 23 (2012) 1.

[9] O.I. Kolodiazhnyi, V.P. Kukhar, A.O. Kolodiazhna, Tetrahedron: Asymmetry 25 (2014) 865.

[10] K.M. Pietrusiewicz, M. Zablocka, Chem. Rev. 94 (1994) 1375.

[11] W. Tang, B. Qu, A.G. Capacci, S. Rodriguez, X. Wei, N. Haddad, B. Narayanan, S. Ma, N. Grinberg, N.K. Yee, D. Krishnamurthy, C.H. Senanayake, Org. Lett. 12 (2010) 176.

[12] W. Tang, A.G. Capacci, A. White, S. Ma, S. Rodriguez, B. Qu, J. Savoie, N.D. Patel, X. Wei, N. Haddad, N. Grinberg, N.K. Yee, D. Krishnamurthy, C.H. Senanayake, Org. Lett. 12 (2010) 1104.

[13] Z. Pakulski, O.M. Demchuk, J. Frelek, R. Luboradzki, K.M. Pietrusiewicz, Eur. J. Org. Chem. 2004 (2004) 3913. 
[14] K. Tani, L.D. Brown, J. Ahmed, J.A. Ibers, M. Yokota, A. Nakamura, S. Otsuka, J. Am. Chem. Soc. 99 (1977) 7876.

[15] E. Duran, E. Gordo, J. Granell, M. Font-Bardia, X. Solans, D. Velasco, F. LopezCalahorra, Tetrahedron: Asymmetry 12 (2001) 1987.

[16] F. Doro, M. Lutz, J.N.H. Reek, A.L. Spek, P. van Leeuwen, Eur. J. Inorg. Chem. (2008) 1309.

[17] F. Robin, F. Mercier, L. Ricard, F. Mathey, M. Spagnol, Chem. A Eur. J. 3 (1997) 1365.

[18] F. Bienewald, L. Ricard, F. Mercier, F. Mathey, Tetrahedron: Asymmetry 10 (1999) 4701.

[19] G. He, K.F. Mok, P.-H. Leung, Organometallics 18 (1999) 4027.

[20] T. Imamoto, K.V.L. Crépy, K. Katagiri, Tetrahedron: Asymmetry 15 (2004) 2213.

[21] D. Liu, X. Zhang, Eur. J. Org. Chem. 2005 (2005) 646.

[22] F.G. Holliman, F.G. Mann, J. Chem. Soc. (1947) 1634.

[23] F.A. Hart, F.G. Mann, J. Chem. Soc. (1955) 4107.

[24] J.R. Corfield, J.R. Shutt, S. Trippett, J. Chem. Soc. Chem. Commun. (1969) 789.

[25] K.D. Berlin, C.-H. Chen, J. Org. Chem. 36 (1971) 2791.

[26] K.L. Marsi, H. Tuinstra, J. Org. Chem. 40 (1975) 1843.

[27] N. Gurusamy, K.D. Berlin, J. Am. Chem. Soc. 104 (1982) 3114.

[28] W. Tang, X. Zhang, Angew. Chem. Int. Ed. 41 (2002) 1612.

[29] M.J. Burk, J. Am. Chem. Soc. 113 (1991) 8518.

[30] M.J. Burk, J.E. Feaster, W.A. Nugent, R.L. Harlow, J. Am. Chem. Soc., 115 (1993) 10125.

[31] G. Hoge, J. Am. Chem. Soc. 126 (2004) 9920.

[32] G. Hoge, B. Samas, Tetrahedron: Asymmetry 15 (2004) 2155. 
[33] R.A. Baber, M.F. Haddow, A.J. Middleton, A.G. Orpen, P.G. Pringle, A. Haynes, G.L. Williams, R. Papp, Organometallics 26 (2006) 713.

[34] M. Carreira, M. Charernsuk, M. Eberhard, N. Fey, R.v. Ginkel, A. Hamilton, W.P. Mul, A.G. Orpen, H. Phetmung, P.G. Pringle, J. Am. Chem. Soc. 131 (2009) 3078.

[35] E. Robé, C. Hegedüs, J. Bakos, Y. Coppel, J.-C. Daran, M. Gouygou, Inorg. Chim. Acta $361(2008) 1861$.

[36] T. Novák, J. Schindler, V. Ujj, M. Czugler, E. Fogassy, G. Keglevich, Tetrahedron: Asymmetry 17 (2006) 2599.

[37] T. Novák, V. Ujj, J. Schindler, M. Czugler, M. Kubinyi, Z.A. Mayer, E. Fogassy, G. Keglevich, Tetrahedron: Asymmetry 18 (2007) 2965.

[38] V. Ujj, J. Schindler, T. Novák, M. Czugler, E. Fogassy, G. Keglevich, Tetrahedron: Asymmetry 19 (2008) 1973.

[39] V. Ujj, P. Bagi, J. Schindler, J. Madarász, E. Fogassy, G. Keglevich, Chirality 22 (2010) 699.

[40] P. Bagi, A. Fekete, M. Kállay, D. Hessz, M. Kubinyi, T. Holczbauer, M. Czugler, E. Fogassy, G. Keglevich, Chirality 26 (2014) 174.

[41] P. Bagi, M. Kállay, D. Hessz, M. Kubinyi, T. Holczbauer, M. Czugler, E. Fogassy, G. Keglevich, Tetrahedron: Asymmetry 25 (2014) 318.

[42] P. Bagi, A. Fekete, M. Kállay, D. Hessz, M. Kubinyi, T. Holczbauer, M. Czugler, E. Fogassy, G. Keglevich, Heteroatom Chem. 26 (2015) 79.

[43] P. Bagi, A. Laki, G. Keglevich, Heteroatom Chem. 24 (2013) 179.

[44] V. Ujj, A. Kerényi, A. Laki, E. Fogassy, G. Keglevich, Lett. Org. Chem. 7 (2010) 110.

[45] P. Pongrácz, L. Kollár, A. Kerényi, V. Kovács, V. Ujj, G. Keglevich, J. Organomet. Chem. 696 (2011) 2234. 
[46] G. Keglevich, P. Bagi, Á. Szöllősy, T. Körtvélyesi, P. Pongrácz, L. Kollár, L. Drahos, J. Organomet. Chem. 696 (2011) 3557.

[47] P. Bagi, T. Kovács, T. Szilvási, P. Pongrácz, L. Kollár, L. Drahos, E. Fogassy, G. Keglevich, J. Organomet. Chem. 751 (2014) 306.

[48] P. Bagi, T. Szilvási, P. Pongrácz, L. Kollár, L. Drahos, G. Keglevich, Curr. Org. Chem. 18 (2014) 1529.

[49] G. Keglevich, H. Szelke, Á. Bálint, T. Imre, K. Ludányi, Z. Nagy, M. Hanusz, K. Simon, V. Harmat, L. Tőke, Heteroatom Chem. 14 (2003) 443.

[50] R.A. Sheldon, Chirotechnology: Industrial Synthesis of Optically Active Compounds, Marcel Dekker, New York, 1993.

[51] Mercury CSD 3.5.1 (Build RC5): C.F. Macrae, I.J. Bruno, J.A. Chisholm, P.R. Edgington, P. McCabe, E. Pidcock, L. Rodriguez-Monge, R. Taylor, J. van de Streek, P.A. Wood, J. Appl. Cryst. 41 (2008) 466.

[52] A. Gavezzotti, Acc. Chem. Res. 27 (1994) 309.

[53] A. Gavezzotti, G. Filippini, J. Phys. Chem. 98 (1994) 4831.

[54] J.P. Stewart, J. Mol. Mod. 13 (2007) 1173.

[55] M. Korth, J. Chem. Theory Comput. 6 (2010) 3808.

[56] MOPAC2012, J.J.P. Stewart, Stewart Computational Chemistry; Colorado Springs, CO, USA, Version 15.089L web: http://OpenMOPAC.net.

[57] J.D.C. Maia, G.A. Urquiza Carvalho, C.P. Mangueira, S.R. Santana, L.A.F. Cabral, G.B. Rocha, J. Chem. Theory Comput. 8 (2012) 3072.

[58] R. Engel, in: R. Engel (Ed.), Handbook of Organophosphorus Chemistry, Marcel Dekker, New York, 1992, pp. 193.

[59] T. Imamoto, T. Kusumoto, N. Suzuki, K. Sato, J. Am. Chem. Soc. 107 (1985) 5301.

[60] G.M. Sheldrick, Acta Cryst. A, 64 (2008) 112. 
[61] A. Spek, Acta Cryst. D, 65 (2009) 148.

[62] SCHAKAL (E. Keller, University of Freiburg (Breisgau), Germany, 1995).

[63] Marvin 6.1.0, ChemAxon (http://www.chemaxon.com).

[64] M.J. Frisch, G.W. Trucks, H.B. Schlegel, G.E. Scuseria, M.A. Robb, J.R. Cheeseman, G. Scalmani, V. Barone, B. Mennucci, G.A. Petersson, H. Nakatsuji, M. Caricato, X. Li, H.P. Hratchian, A.F. Izmaylov, J. Bloino, G. Zheng, J.L. Sonnenberg, M. Hada, M. Ehara, K. Toyota, R. Fukuda, J. Hasegawa, M. Ishida, T. Nakajima, Y. Honda, O. Kitao, H. Nakai, T. Vreven, J.A. Montgomery, Jr., J.E. Peralta, F. Ogliaro, M. Bearpark, J.J. Heyd, E. Brothers, K.N. Kudin, V.N. Staroverov, R. Kobayashi, J. Normand, K. Raghavachari, A. Rendell, J.C. Burant, S.S. Iyengar, J. Tomasi, M. Cossi, N. Rega, J.M. Millam, M. Klene, J.E. Knox, J.B. Cross, V. Bakken, C. Adamo, J. Jaramillo, R. Gomperts, R.E. Stratmann, O. Yazyev, A.J. Austin, R. Cammi, C. Pomelli, J.W. Ochterski, R.L. Martin, K. Morokuma, V.G. Zakrzewski, G.A. Voth, P. Salvador, J.J. Dannenberg, S. Dapprich, A.D. Daniels, Ö. Farkas, J.B. Foresman, J.V. Ortiz, J. Cioslowski, D.J. Fox, Gaussian 09, Revision B.01, Gaussian, Inc., Wallingford CT, 2010.

[65] MRCC, a quantum chemical program suite written by M. Kállay, Z. Rolik, I. Ladjánszki, L. Szegedy, B. Ladóczki, J. Csontos, B. Kornis. See also Z. Rolik, L. Szegedy, I. Ladjánszki, B. Ladóczki, M. Kállay, J. Chem. Phys. 2013, 139, 094105 as well as: www.mrcc.hu.

[66] T.A. Halgren, J. Comput. Chem. 20 (1999) 720.

[67] C. Adamo, V. Barone, J. Chem. Phys. 110 (1999) 6158.

[68] J.P. Perdew, K. Burke, M. Ernzerhof, Phys. Rev. Lett. 77 (1996) 3865.

[69] R.A. Kendall, T.H. Dunning, R.J. Harrison, J. Chem. Phys. 96 (1992) 6796.

[70] S. Miertuš, E. Scrocco, J. Tomasi, Chem. Phys. 55 (1981) 117. 
[71] R.E. Stratmann, G.E. Scuseria, M.J. Frisch, J. Chem. Phys. 109 (1998) 8218.

[72] M.J. Frisch, J.A. Pople, J.S. Binkley, J. Chem. Phys. 80 (1984) 3265.

[73] O. Vahtras, J. Almlöf, M.W. Feyereisen, Chem. Phys. Lett. 213 (1993) 514.

[74] A.D. Becke, J. Chem. Phys. 107 (1997) 8554.

[75] S. Grimme, J. Comput. Chem. 27 (2006) 1787.

[76] T.H. Dunning, J. Chem. Phys. 90 (1989) 1007.

[77] J.-D. Chai, M. Head-Gordon, Phys. Chem. Chem. Phys. 10 (2008) 6615.

[78] K.L. Schuchardt, B.T. Didier, T. Elsethagen, L. Sun, V. Gurumoorthi, J. Chase, J. Li, T.L. Windus, J. Chem. Inf. Model. 47 (2007) 1045.

[79] M. Hanwell, D. Curtis, D. Lonie, T. Vandermeersch, E. Zurek, G. Hutchison, J. Cheminform. 4 (2012) 17. 